\title{
Selective coactivation of estrogen-dependent transcription by CITED1 CBP/p300-binding protein
}

\author{
Tetsuro Yahata, ${ }^{1}$ Wenlin Shao, ${ }^{2}$ Hideaki Endoh, ${ }^{3}$ Jingyung Hur, ${ }^{1}$ Kathryn R. Coser, ${ }^{1}$ Huiping Sun, ${ }^{1}$ \\ Yoshitaka Ueda, ${ }^{3}$ Shigeaki Kato, ${ }^{4}$ Kurt J. Isselbacher, ${ }^{1}$ Myles Brown, ${ }^{2}$ and Toshi Shioda ${ }^{1,5}$ \\ ${ }^{1}$ Laboratory of Tumor Biology, Massachusetts General Hospital Cancer Center, Charlestown, Massachusetts 02129, USA; \\ ${ }^{2}$ Department of Adult Oncology, Dana-Farber Cancer Institute, Boston, Massachusetts 02115, USA; ${ }^{3}$ Molecular Medicine \\ Laboratories, Yamanouchi Pharmaceutical, Ibaraki 305, Japan; ${ }^{4}$ Institute for Molecular and Cellular Biosciences, The \\ University of Tokyo, Tokyo 113, Japan
}

CITED1, a CBP/p300-binding nuclear protein that does not bind directly to DNA, is a transcriptional coregulator. Here, we show evidence that CITED1 functions as a selective coactivator for estrogen-dependent transcription. When transfected, CITED1 enhanced transcriptional activation by the ligand-binding/AF2 domain of both estrogen receptor- $\alpha(E R \alpha)$ and ER $\beta$ in an estrogen-dependent manner, but it affected transcriptional activities of other nuclear receptors only marginally. CITED1 bound directly to ER $\alpha$ in an estrogen-dependent manner through its transactivating domain, and this binding activity was separable from its p300-binding activity. CITED1 was strongly expressed in nulliparous mouse mammary epithelial cells and, when expressed in ER-positive MCF-7 breast cancer cells by transduction, exogenous CITED1 enhanced sensitivity of MCF-7 cells to estrogen, stabilizing the estrogen-dependent interaction between p300 and ER $\alpha$. The estrogen-induced expression of the transforming growth factor- $\alpha$ (TGF- $\alpha$ ) mRNA transcript was enhanced in the CITED1-expressing MCF-7 cells, whereas estrogen-induced expression of the mRNA transcripts for progesterone receptor or pS2 was not affected. Chromatin immunoprecipitation assay revealed that endogenous CITED1 is recruited to the chromosomal TGF- $\alpha$ promoter in MCF-7 cells in an estrogen-dependent manner but not to the $p S 2$ promoter. These results suggest that CITED1 may play roles in regulation of estrogen sensitivity in a gene-specific manner.

[Key Words: CITED protein; CBP/p300; estrogen receptor; nuclear receptor; transcriptional coactivator; transforming growth factor- $\alpha$ ]

Received April 24, 2001; revised version accepted August 2, 2001.

The CITED family (CBP/p300-interacting transactivators with glutamic acid [E]/aspartic acid [ㅁ] -rich C-terminal domain) consists of four nuclear proteinsCITED1 (formerly MSG1; Shioda et al. 1996; Dunwoodie et al. 1998), CITED2 (formerly MRG1 or p35srj; Shioda et al. 1997a; Sun et al. 1998; Bhattacharya et al. 1999; Schlange et al. 2000), CITED3 (Andrews et al. 2000), and CITED4 (formerly MRG2; Yahata et al. 2000)-that share a strictly conserved C-terminal transcriptional activating domain (designated as the CR2 domain) that binds to the $\mathrm{CBP} / \mathrm{p} 300$ transcriptional integrators (Bhattacharya et al. 1999; Yahata et al. 2000). When tethered to heterologous DNA-binding domains, all CITED proteins strongly activate transcription in a manner depen-

${ }^{5}$ Corresponding author.

E-MAIL shioda@helix.mgh.harvard.edu; FAX (617) 726-5637.

Article and publication are at http://www.genesdev.org/cgi/doi/10.1101/ gad.906301. dent on the CR2 domain and CBP/p300 (Shioda et al. 1998; Yahata et al. 2000; T. Yahata, K.R. Coser, and T. Shioda, unpubl.). However, the fact that no CITED protein has any significant DNA-binding motifs or detectable affinity to DNA leads to the hypothesis that the CITED proteins may interact with DNA-binding proteins and function as transcriptional coactivators. Supporting this hypothesis, CITED1 enhances transcription mediated by the SMAD transcription factors in a manner dependent on CBP/p300 (Shioda et al. 1998). CITED2 binds to the LIM domain of the Lhx2 transcription factor and enhances Lhx2-dependent transcription of the LH/ FSH glycoprotein $\alpha$-subunit gene (Glenn and Maurer 1999). On the other hand, Bhattacharya et al. (1999) showed that binding of CITED2 to CBP/p300 competes with interaction between the HIF-1 transcription factor and $\mathrm{CBP} / \mathrm{p} 300$, resulting in suppression of HIF-1-dependent transcription. Because expression of the CITED proteins shows remarkable tissue specificity and cytokine 
dependency, it has been suggested that the CITED proteins may play roles in tissue-specific and/or cytokinedependent regulation of $\mathrm{CBP} / \mathrm{p} 300$-dependent gene expression (Dunwoodie et al. 1998; Fenner et al. 1998; Li et al. 1998; Sun et al. 1998; Bhattacharya et al. 1999; Andrews et al. 2000).

Based on this hypothesis that the CITED proteins may function as coactivators of $\mathrm{CBP} / \mathrm{p} 300$-dependent transcription factors, we examined possible effects of the CITED proteins on ligand-induced transcriptional activation mediated by nuclear receptors (NRs). The NR superfamily of transcription factors regulates transcriptional activation and suppression in a manner dependent on binding to specific ligands such as steroid hormones. A conserved amphipathic $\alpha$-helical structure within their ligand-binding domain (LBD), referred to as activation function 2 (AF2), is required for their ligand-dependent transcriptional activation, whereas another region, activation function 1 (AF1), is responsible for their ligand-independent transactivating activity. NRs require increasing numbers of coactivator proteins for their transcriptional activating activities (Freedman 1999; Glass and Rosenfeld 2000). Such coactivators, which usually function as multiprotein complexes, include histone acetyltransferases (the p160 family coactivators SRC-1/ NcoA-1, TIF2/GRIP1/NcoA-2, and pCIP/ACTR/AIB1/ RAC3/NCoA-3, the p300 and CBP transcriptional integrators, and the $\mathrm{CBP} / \mathrm{p} 300$-associated factor $\mathrm{pCAF}$ ), ATPdependent chromatin remodeling complexes (SWI/SNF) BRG complexes), and mediator-like protein complexes (DRIP/TRAP/ARC/PBP complexes). The functional importance of $\mathrm{CBP} / \mathrm{p} 300$ in NR-mediated transcriptional activation has been shown in vivo (Chakravarti et al. 1996) and in vitro (Kraus and Kadonaga 1998). The histone acetyltransferases and the ATP-dependent chromatin remodeling complexes may relieve chromatin-mediated transcriptional repression, whereas the mediatorlike complexes may recruit general transcription factors and RNA polymerase II holoenzyme to promoters. Dynamic and cyclic recruitment of estrogen-bound estrogen receptor- $\alpha(E R \alpha)$ and these coactivators to ER target promoters has been demonstrated recently, supporting a model that these coactivator complexes act in a combinatorial manner rather than independently (Shang et al. 2000). There are a number of additional proteins that have been proposed as NR coactivators based on simple criteria of ligand-dependent binding to NRs and/or ability to synergize NR-mediated transactivation evaluated by transfection-based assays: They include HMG factors, MEF2, cyclin D, ARA5Y, SNURF, NcoA-62, PC2, and PC4 (see Glass and Rosenfeld 2000 and references therein). Several coactivators have relative preferences for a subset of NRs, that is, ARA70 selectively enhances transcription mediated by androgen receptor (Yeh et al. 1999), and NRIF3 interacts selectively with thyroid hormone receptor and retinoid X receptor (Li et al. 1999). However, most of the ligand-dependent coactivators do not show strong selectivity in target NRs.

In the present study we provide evidence that CITED1 functions as a selective ER coactivator, proposing its pos- sible roles in cell- and gene-specific regulation of estrogen-dependent transcription.

\section{Results}

The CITED proteins selectively enhance agonist-dependent transactivation mediated by the LBD/AF2 domain of ERs

To determine whether the CITED proteins affect transcriptional functions of NRs, we evaluated effects of the CITED proteins on transcription activated by the AF1 or LBD/AF2 domains of NRs. Thus, AF1 or LBD/AF2 domains from selected NRs were fused to the GAL4 DNAbinding domain (GAL4DBD), and their transactivating activities were evaluated by transfection-based reporter assays in the presence or absence of cotransfection of CITED proteins (Fig. 1A,B). The CITED proteins showed no effect on ligand-independent transactivation mediated by AF1 of ER $\alpha$, androgen receptor, or retinoic acid receptor $\alpha$. They had only a marginal effect on liganddependent transactivation mediated by the LBD/AF2 domains of androgen receptor, retinoic acid receptor- $\alpha$, retinoid $\mathrm{X}$ receptor, mineralocorticoid receptor, or vitamin D3 receptor. Strikingly, however, all of the CITED proteins significantly enhanced estrogen-dependent transactivation mediated by the LBD/AF2 domain of both ER $\alpha$ and ER $\beta$ without affecting the basal transcription observed in the absence of estrogen. The relatively weaker ER-coactivating activities of CITED2 and CITED3 compared to CITED1 or CITED4 were likely owing to their extremely short protein half-lives in mammalian cells, resulting in poor protein expression in these experiments (Bhattacharya et al. 1999; K.R. Coser and T. Shioda, unpubl.). This speculation was supported by an observation that the ER-coactivating effect of CITED1 was dependent on dose of CITED1 expression (Fig. 1C). These results suggest that the coactivating activity of the CITED proteins is relatively selective to the LBD/AF2 domain of ERs. Because CITED1 is stable in mammalian cells and has strong ER-coactivating activity and this molecule has been studied most extensively among the CITED family of proteins, we have chosen CITED1 for further characterization.

Recent studies have revealed that binding of estrogen agonists to the LBD of ERs induces major conformational changes that stabilize interactions between ERs and LBD-binding coactivators. Estrogen antagonists, such as tamoxifen and raloxifene (partial agonists) or ICI164384 (pure antagonist), also bind to LBD of ERs but induce aberrant conformational changes that preclude coactivator binding (Freedman 1999; Glass and Rosenfeld 2000). As shown in Figure 1D, those estrogen antagonists failed to induce LBD/AF2-mediated transactivation in the presence or absence of CITED1, whereas transcription induced by the natural estrogen agonist (17 $\beta$-estradiol) was remarkably enhanced by CITED1. These results suggest that the functional interaction of CITED1 with ER $\alpha$-LBD/AF2 requires the correct, activeform conformation of liganded ER. 
Yahata et al.

To obtain insights as to whether the mechanism of the CITED1 activity to enhance transcriptional activation mediated by ER $\alpha$-LBD/AF2 involves $\mathrm{CBP} / \mathrm{p} 300$, we determined effects of p300 on this transactivation by transfection-based assays (Fig. 1E). In the absence of CITED1, the effect of p300 transfection on this transactivation was minimal. When a limited amount of CITED1 alone was transfected, the transactivation was enhanced $\sim$ fourfold and, as expected, additional transfection of p300 further augmented it $\sim 1.8$-fold. These results showed a synergistic effect of $\mathrm{p} 300$ on the ER $\alpha$-LBD/AF2 coactivation by CITED1, suggesting an involvement of p300 land

A

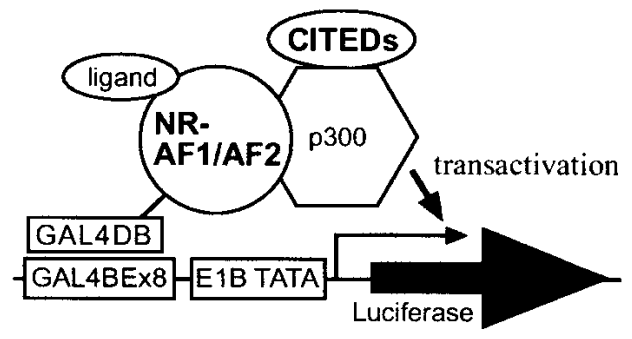

B
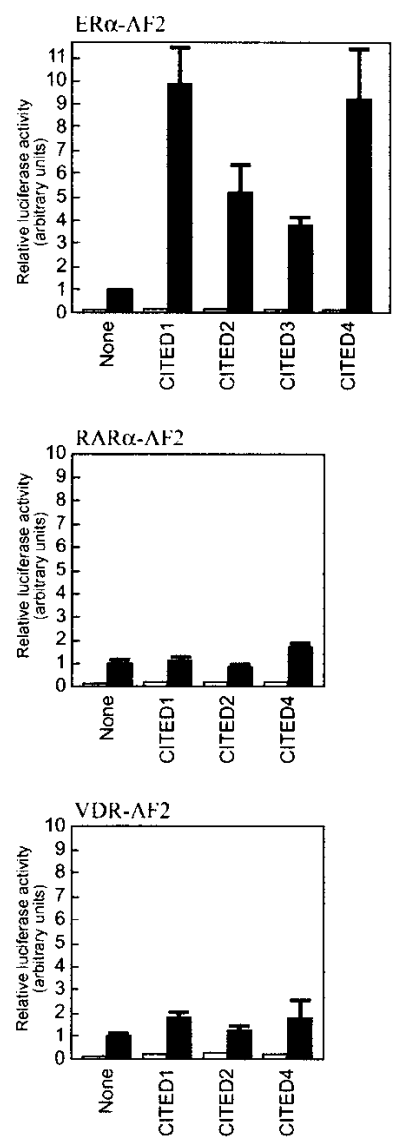

C

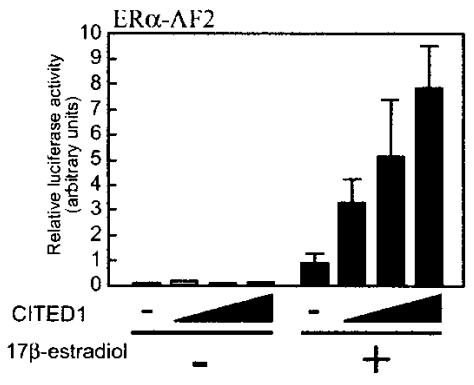

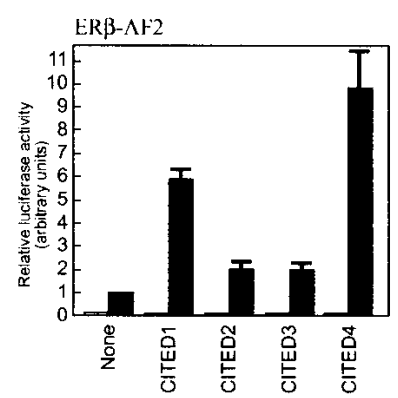
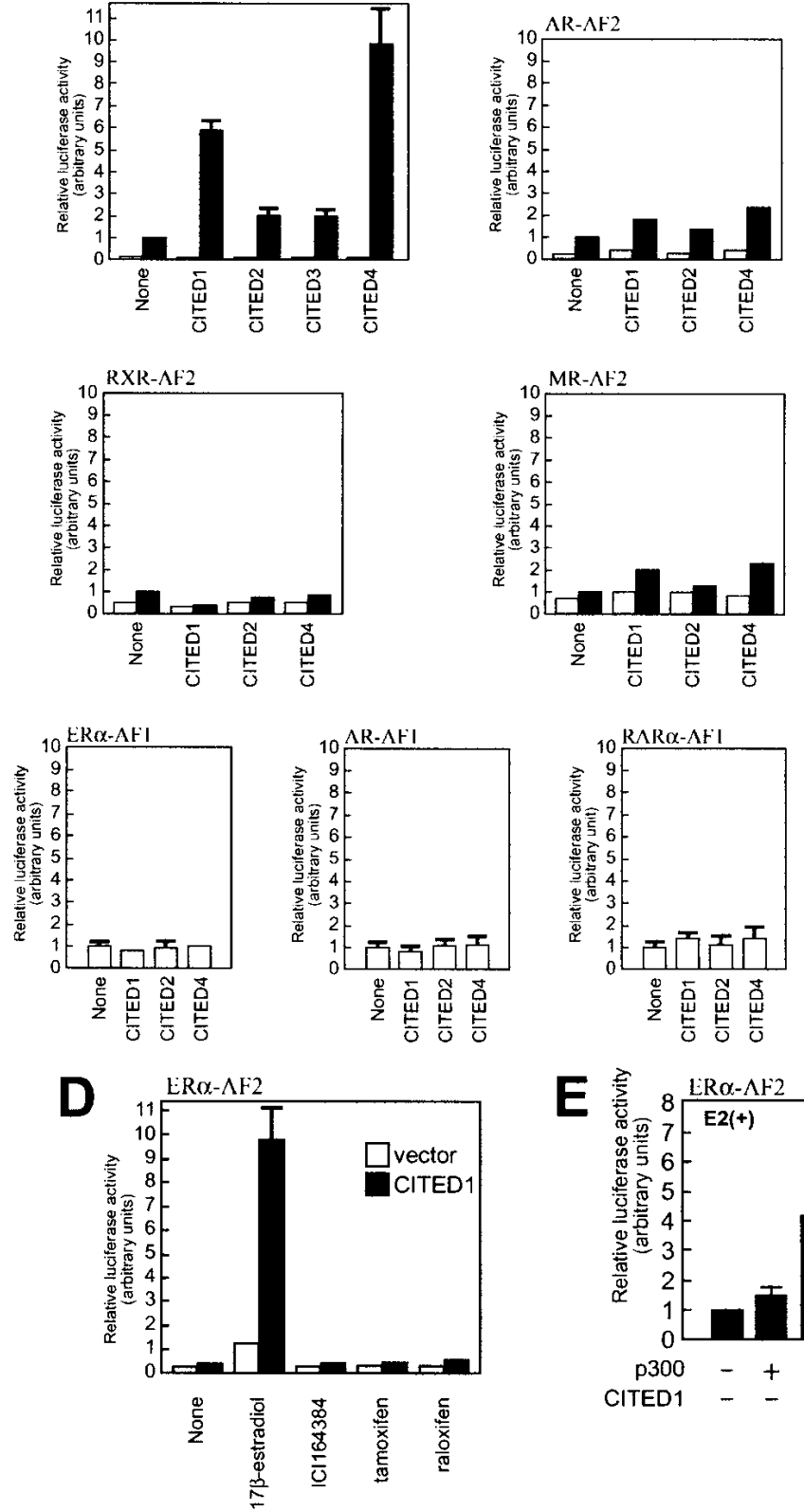
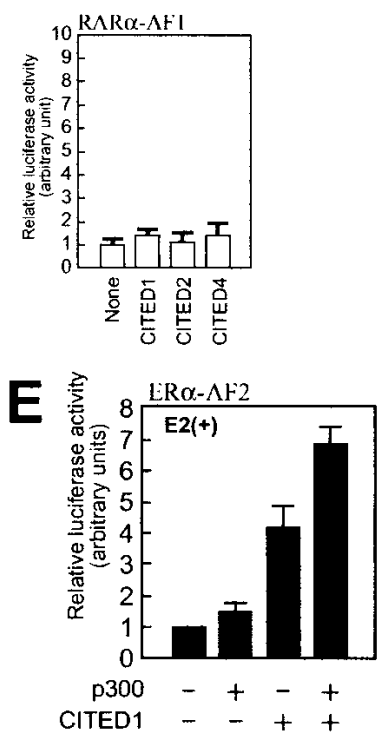
probably CBP as well) in the mechanism of ER coactivation by CITED1.

\section{CITED1 enhances estrogen-dependent transactivation mediated by endogenous ERs in a manner dependent on core promoters located downstream of estrogen response elements}

We next attempted to determine whether CITED1 enhances estrogen-dependent transcription mediated by endogenous (hence, full-length) ERs. Thus, MCF-7 cells (ER-positive) or COS-1 cells (ER-negative) were transfected with ER-dependent luciferase reporter plasmids and varying amounts of CITED1. A very small amount of endogenous CITED1 was detectable in MCF-7 cells when analyzed by Western blotting (see Fig. 7A, below), but not in COS-1 cells (data not shown). Cells were then incubated in the presence or absence of estrogen, followed by luciferase assay (Fig. 2A). To evaluate possible promoter dependency of the ER-coactivating activity of CITED1, in this experiment we used three ER-dependent luciferase reporter plasmids with different core promoters, namely, pEREG-Luc harboring one copy of estrogen response element (ERE) followed by the $\beta$-globin promoter (ERE-globin promoter; Eckner et al. 1994); pEREtk harboring one copy of ERE followed by the herpes simplex virus thymidine kinase promoter (ERE-tk promoter), and p3XERE-E1BTATA harboring three copies of ERE followed by the adenovirus E1B TATA box (EREE1B promoter; Kalkhoven et al. 1998). In MCF-7 cells, cotransfection of CITED1 enhanced estrogen-dependent transcription from the ERE-tk and ERE-E1B promoters in a manner dependent on the dose of CITED1. In contrast, in COS-1 cells, there was no effect of CITED1 cotransfection on estrogen-dependent transcription from any of these promoters, although comparable amounts of transfected CITED1 protein were expressed in these two cell lines (Fig. 2B). Interestingly, estrogen-induced transcription from the ERE-globin promoter was not at all affected by CITED1 cotransfection either in MCF-7 cells or in COS-1 cells. These results showed that CITED1 is capable of enhancing estrogen-dependent transactivation mediated by endogenous ERs. They also implied possible promoter dependency of the ER-coactivating activity of CITED1.

\begin{abstract}
The $N$-terminal region of the conserved CR2 domain of CITED1 is required for functional interaction with ERs but not with CBP/p300
\end{abstract}

We next attempted to determine amino acid sequences of CITED1 that are required for the functional interaction with ERs. Unexpectedly, no CITED proteins possess the LXXLL signature motif that is necessary and sufficient for binding of many ligand-dependent coactivators to NRs (Glass and Rosenfeld 2000). Because all members of the CITED family showed ER-coactivating activity (Fig. 1B), we assumed that ERs would interact with amino acid sequences that are conserved among, and unique to, the CITED proteins, prompting us to speculate that ERs may interact with the CR2 domain (Bhattacharya et al. 1999; Yahata et al. 2000). To test this, we determined whether a deletion of the CR2 domain from CITED1 results in loss of its ER-coactivating activity. As expected, such a mutation ( $\Delta \mathrm{CR} 2)$ completely suppressed ER-coactivating activity of CITED1 (Fig. 3C) without affecting expression of CITED1 protein (Fig. 3B). To determine ER-interacting regions of CITED1 more precisely, we introduced systematic alanine-scan mutations in the CR2 domain and evaluated their effects on the ER-coactivating activity. Such mutations in the Nterminal region of the CR2 domain did not affect the amount of CITED1 protein expression (Fig. 3A,B). However, mutations in the C-terminal region of the CR2 domain were frequently associated with a marked reduction in the amount of CITED1 protein expression, making it difficult to obtain systematic evaluations in this region (K.R. Coser and T. Shioda, unpubl.). Interestingly, only one of the mutations (mut2) in the N-terminal region of the CR2 domain completely suppressed the ERcoactivating activity, whereas others affected this activity only marginally (Fig. 3C). These results indicate a critical role of the $\mathrm{N}$-terminal region of the CR2 domain in the functional interaction between CITED1 and ERs, although our experiments did not preclude possible additional contributions by other regions of CITED1 to this

\footnotetext{
Figure 1. The CITED proteins enhance estrogen-dependent transcription mediated by the LBD/AF2 domain of ERs. (A) Schematic representation of the assay. NIH3T3 cells were transfected with the GAL4DBD fusion of the AF1 or AF2 domain of nuclear receptors (NR-AF1/AF2), the CITED proteins, p300 (for panel $E$ only), together with luciferase reporter plasmid pGLUC8 harboring eight repeats of the GAL4-binding element (GAL4BE) followed by the E1B TATA box. Cells were cultured in hormone-free medium for $24 \mathrm{~h}$ after transfection, followed by culture in the presence or absence of ligands for an additional $24 \mathrm{~h}$ before luciferase assay. (B) The CITED proteins selectively enhance estrogen-dependent transcription. Cells were incubated in the presence (filled bars) or absence (open bars) of cognate ligands: $100 \mathrm{nM} \mathrm{17 \beta -estradiol} \mathrm{for} \mathrm{ER} \alpha$ and ER $\beta ; 10 \mathrm{nM}$ dihydroxyandrostendione for androgen receptor (AR); $100 \mathrm{nM}$ all-trans-retinoic acid for retinoic acid receptor $\alpha(\mathrm{RAR} \alpha) ; 100 \mathrm{nM}$ 9-cis-retinoic acid for retinoid X receptor $\alpha(\mathrm{RXR} \alpha) ; 100 \mathrm{nM}$ $d$-aldosterone for mineralocorticoid receptor (MR); and $10 \mathrm{nM} \mathrm{1,25-dihydroxy} \mathrm{vitamin} \mathrm{D3} \mathrm{for} \mathrm{vitamin} \mathrm{D} \mathrm{receptor} \mathrm{(VDR).} \mathrm{(C)} \mathrm{CITED1}$ enhances estrogen-dependent transcription by the LBD/AF2 domain of ER $\alpha$ in a dose-dependent manner. Cells were cotransfected with pGLUC8, GAL4DBD-ER $\alpha$-AF2, and varying amounts of CITED1, then stimulated with $100 \mathrm{nM} 17 \beta$-estradiol. (D) CITED1 enhances $\mathrm{ER} \alpha$-mediated transcription only in the presence of agonist. Cells were cotransfected with pGLUC8, GAL4DBD-ER $\alpha-A F 2$, CITED1 (filled bars) or a control vector (open bars), then stimulated with ligands (100 nM 17 $\beta$-estradiol, $100 \mathrm{nM} \mathrm{ICI164384,} 100 \mathrm{nM}$ tamoxifen, or $100 \mathrm{nM}$ raloxifene). (E) p300 synergistically augments the enhancement of ER $\alpha$ /AF2-mediated transcription by CITED1. Cells were cotransfected with pGLUC8, GAL4DBD-ER $\alpha$-AF2, with or without CITED1 or p300, then stimulated with $100 \mathrm{nM} 17 \beta$-estradiol (E2).
} 
Yahata et al.

A
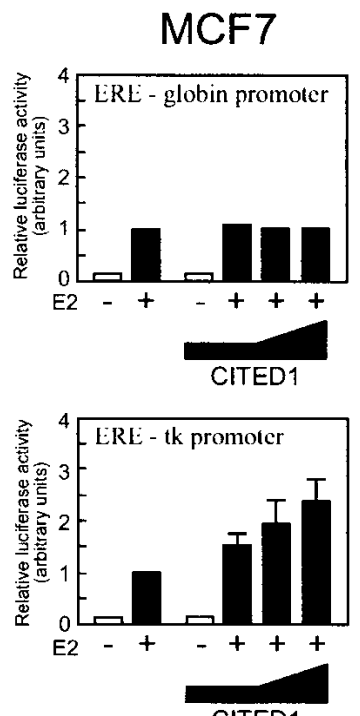

CITED1

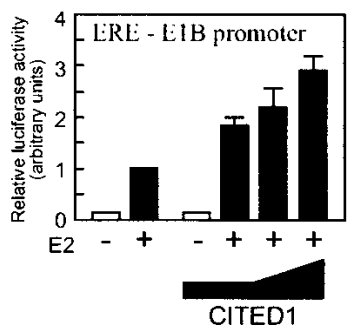

B

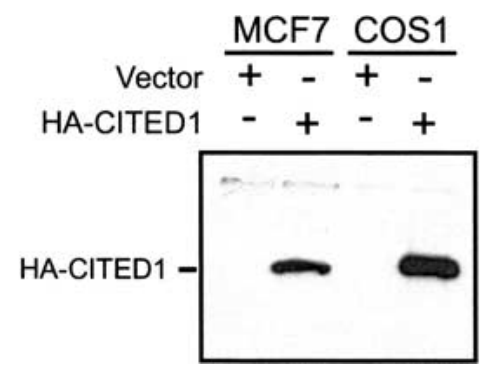

Figure 2. (A) CITED1 enhances estrogen-dependent transcription mediated by the endogenous ERs. MCF-7 and COS-1 cells were transfected with luciferase reporter plasmids harboring ER-binding elements (ERE) located upstream of core promoters (globin, thymidine kinase [tk], or adenovirus E1B) together with varying amounts of HA-tagged CITED1. Cells were then stimulated with $100 \mathrm{nM} 17 \beta$-estradiol (E2) for $24 \mathrm{~h}$ before luciferase assay. $(B)$ Expression of HA-tagged CITED1 protein in MCF-7 and COS-1 cells. The largest amount of the expression plasmid for HA-CITED1 or the same amount of empty vector was transfected to MCF-7 and COS-1 cells. Cell lysates were prepared 24 $\mathrm{h}$ after transfection, and equal amounts of total cellular proteins were subjected to anti-HA Western blotting.

interaction. It should be noted that the amino acid sequence around the critical mut2 mutation is not a canonical LXXLL motif (Fig. 3A).

Because the CITED proteins bind directly to CBP/p300 through the CR2 domain (Bhattacharya et al. 1999; Yahata et al. 2000), we considered a possibility that the observed functional interaction between CITED1 and
ERs might be indirect, involving $\mathrm{CBP} / \mathrm{p} 300$ as an intermediate protein. Therefore, we attempted to determine whether the mutation that suppressed the CITED1-ER interaction concomitantly suppresses the CITED1-p300 interaction. To this end, the CITED1 mutants were tethered directly to the GAL4DBD, and their transcriptional activating activities, which were shown to be totally dependent on interaction with CBP/p300 (Yahata et al. 1996), were evaluated (Fig. 3D). As expected, the $\Delta$ CR2 mutation completely suppressed the CBP/p300-dependent transactivation by GAL4DBD-CITED1. However, the mut2 mutation, as well as other alanine-scan mutations tested, did not at all affect this transactivation. These results indicated that the functional CITED1-ER and CITED1-CBP/p300 interactions are separable, suggesting that $\mathrm{ER} \alpha$ and $\mathrm{CBP} / \mathrm{p} 300$ interact with discrete regions within the CR2 domain.

CITED1 binds to the LBD/AF2 domain of ER $\alpha$ in vivo and in vitro in an estrogen-dependent manner

We attempted to determine whether CITED1 physically interacts with $\mathrm{ER} \alpha$ by transfection-based immunoprecipitation analyses. Thus, COS-1 cells were transfected with HA epitope-tagged CITED1 and FLAG-tagged transactivating domains of $\mathrm{ER} \alpha(\mathrm{AF} 1$ and LBD/AF2) and cultured in the presence or absence of estrogen. The ER $\alpha$ transactivating domains were immunoprecipitated from cell lysates by an anti-FLAG antibody, and coprecipitated CITED1 was detected by anti-HA Western blotting (Fig. 4A). Strikingly, when expressed in COS-1 cells, CITED1 coprecipitated with the LBD/AF2 domain in a manner strictly dependent on the presence of estrogen in the culture. No CITED1 coprecipitation was observed with the AF1 domain in the presence or absence of estrogen. These results indicate that CITED1 physically and specifically interacts with the estrogen-bound LBD/ $\mathrm{AF} 2$ domain of $\mathrm{ER} \alpha$ in vivo.

By a similar approach, we attempted to determine whether CITED1 binds to endogenous (hence, fulllength) ER $\alpha$ in vivo. Thus, ER $\alpha$-positive MCF-7 cells were transfected with HA-tagged CITED1 and cultured in the presence or absence of estrogen. CITED1 was immunoprecipitated from the cell lysate by an anti-HA antibody, and coprecipitated endogenous ER $\alpha$ was detected by Western blotting using an anti-ER $\alpha$ antibody (Fig. 4B). As expected, endogenous $\mathrm{ER} \alpha$ coprecipitated with CITED1 when cells were stimulated by estrogen. Based on these results, we concluded that CITED1 forms protein complexes with $\mathrm{ER} \alpha$ in vivo.

We next determined whether CITED1 binds directly to estrogen-bound $\mathrm{ER} \alpha$ in vitro by the glutathione S-transferase (GST) pull-down assay. We prepared purified protein reagents of polyhistidine epitope-tagged CITED1 (His-CITED1) and GST-tagged AF1 or LBD/AF2 domains of $E R \alpha$. We did not detect contamination of CBP or p300 in these protein reagents by Western blotting (data not shown). As shown in Figure 5A, CITED1 bound to the GST-fusion LBD/AF2 domain in vitro in a manner strictly dependent on the presence of estrogen in 
A
wild type: EEVLMSLVVELGL mut 1: AAVLMSLVVELGL mut 2: EEAAMSLVVELGL mut 3: EEVLAALVVELGL mut 4: EEVLMSAAVELGL mut 5: EEVLMSLAAELGL mut 6: EEVLMSLVAALGL mut 7: EEVLMSLVVEAGL mut 8: EEVLMSLVVELAA

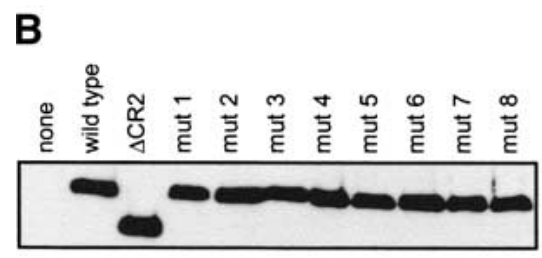

C

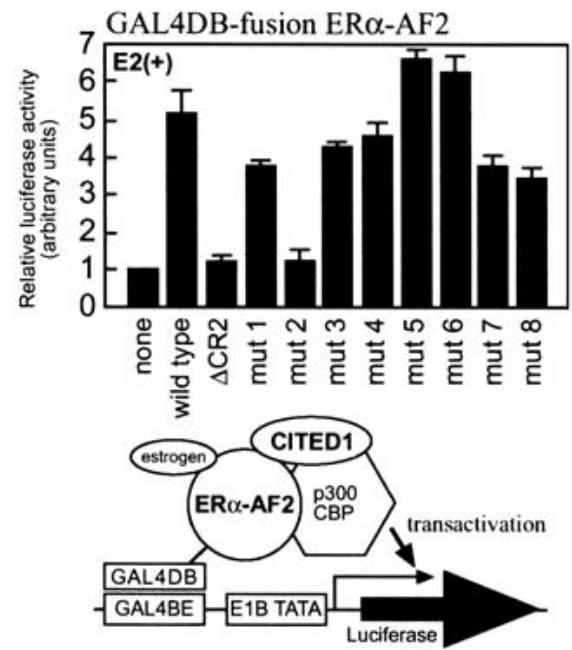

D

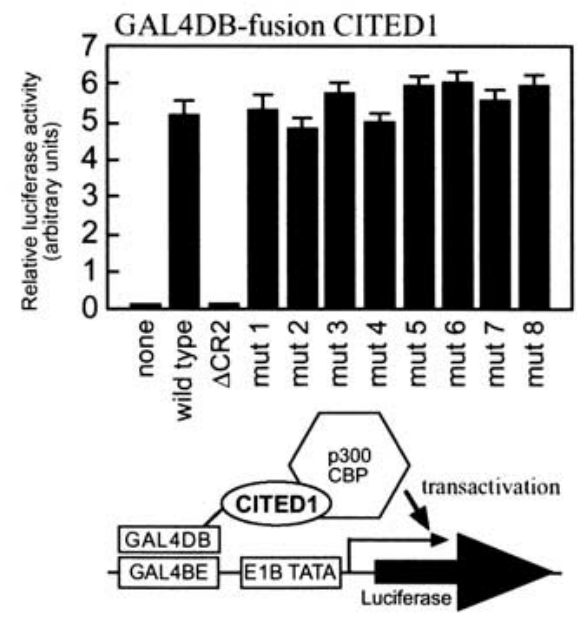

Figure 3. Segregation of the ER $\alpha$-enhancing activity of CITED1 from its p300-dependent transactivating activity. (A) Alanine scan mutants of CITED1. Amino acids 155-167 of CITED1, which locate in the N-terminal region of the CR2 domain, were systematically mutated. $(B)$ Protein expression of the CITED1 alanine scan mutants. CITED1 mutants were transfected into COS-1 cells, and their expression was evaluated by anti-HA Western blotting. $\triangle$ CR2, a CITED1 deletion mutant lacking the CR2 domain. (C) Requirement of amino acids 157-158 (VL) for the ER $\alpha$-enhancing activity of CITED1. Cells were cotransfected with pGLUC8, GAL4DBD-ER $\alpha-A F 2$, and the CITED1 mutants, followed by stimulation with $100 \mathrm{nM} 17 \beta$-estradiol (E2) for $24 \mathrm{~h}$ before luciferase assay. (D) The mut2 CITED1 mutant that lost the ER $\alpha$-enhancing activity retains the p300-dependent transactivating activity. Cells were cotransfected with pGLUC8 and GAL4DBD-fusion CITED1 mutants, followed by luciferase assay.

the binding reaction. There was no interaction of CITED1 with GST-fusion AF1 domain or nonfused GST in the presence or absence of estrogen. These results indicate that CITED1 physically and directly binds to the LBD/ $\mathrm{AF} 2$ domain of $\mathrm{ER} \alpha$ in an estrogen-dependent manner.

The functional interaction of CITED1 with the LBD/ $\mathrm{AF} 2$ domain of $\mathrm{ER} \alpha$ required the $\mathrm{N}$-terminal region of the CR2 domain (see Fig. 3). To characterize the molecular basis of this requirement, we determined whether or not the mut2 mutation of CITED1, which abolished this functional interaction, binds to the LBD/AF2 domain of ER $\alpha$ in vitro. Strikingly, the mut2 mutant CITED1 did not at all bind to the LBD/AF2 domain with or without estrogen (Fig. 5B). These results indicate that the lack of the transcriptional enhancing activity of the mut2 mutant is caused by its inability to bind to ER, confirming the critical importance of the $\mathrm{N}$-terminal region of the CR2 domain of CITED1 in the CITED1-ER $\alpha$ interaction.

\section{CITED1 protein is expressed in nulliparous mouse} mammary gland epithelial cells but rapidly disappears with pregnancy

To obtain insights into the possible biological significance of the ER-coactivating activity of CITED1, we examined by immunohistochemistry whether CITED1 protein is expressed in the major ER-target organs of mice. Although we did not detect significant amounts of CITED1 in uterus or ovary (data not shown), strong expression of CITED1 was observed in nulliparous mouse mammary epithelial cells (Fig. 6A). Practically all mam- mary epithelial cells were positive, and most of them showed nuclear localization of CITED1, with a minor population of cells showing cytosolic staining as well, agreeing with a staining pattern previously reported for human melanoma tissue (Li et al. 1998). Those mammary epithelial cells also strongly expressed ER $\alpha$ (Fig. 6B). Interestingly, however, CITED1-positive cells disappeared rapidly when mice became pregnant; only a minor part of mammary epithelial cells expressed CITED1 in pregnant mice at 11.5 days postcoitum (dpc) (Fig. 6C), and no CITED1 expression was detected in lactating mammary gland (Fig. 6D). On the other hand, a strong expression of CITED4 was observed in lactating mammary epithelial cells (Fig. 6D, insert). The strong expression of CITED1 protein in nulliparous mouse mammary epithelial cells and its rapid disappearance upon pregnancy were also confirmed by anti-CITED1 Western blotting (data not shown). These results imply possible biological roles of CITED1 in nulliparous mammary epithelial cells.

CITED1 stabilizes the estrogen-dependent interaction of ER $\alpha$ and p300 in MCF-7 breast cancer cells and enhances cellular sensitivity to estrogen

Plasma estrogen levels are far lower in nulliparous mice than in pregnant mice. Because expression of CITED1 protein is stronger in nulliparous mice but rapidly lost with pregnancy, we hypothesized that CITED1 may play roles in regulation of cellular sensitivity to estrogen. Therefore, we compared the estrogen sensitivity of ER $\alpha$ - 
Yahata et al.

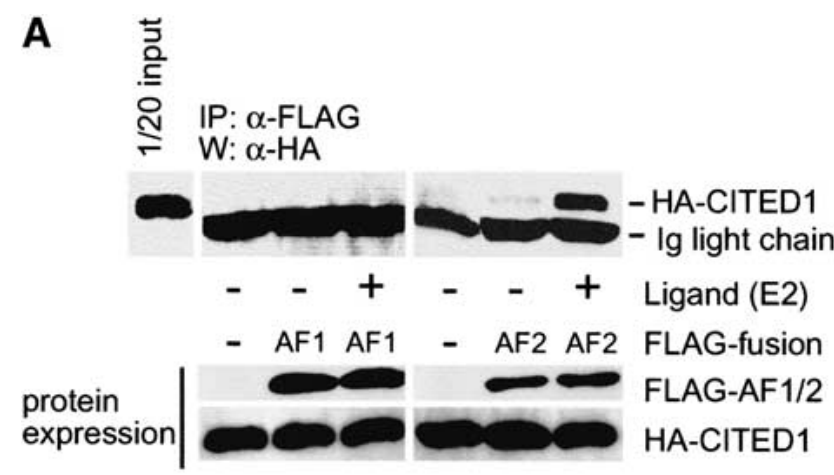

B

$$
\text { IP: anti-HA }
$$

Western: anti-ER $\alpha$

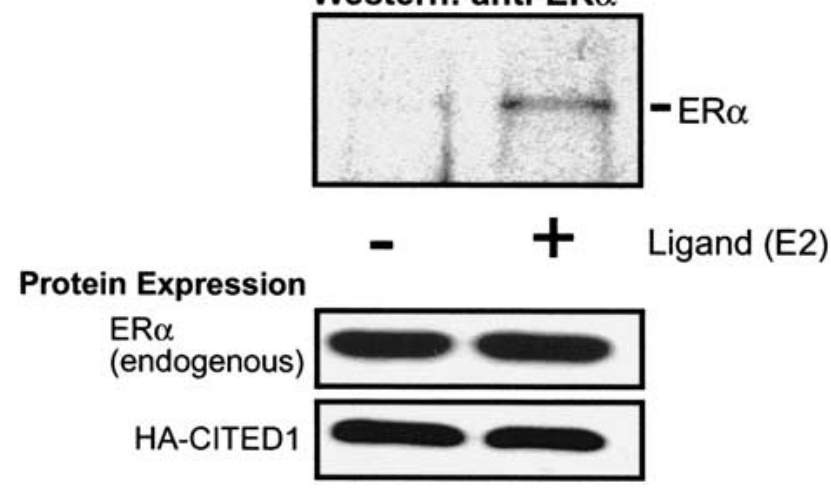

Figure 4. Estrogen-dependent interaction of CITED1 with ER $\alpha$ in vivo. $(A)$ CITED1 interacts with the LBD/AF2 domain of ER $\alpha$ in an estrogen-dependent manner. COS-1 cells were transfected with the FLAG-tagged AF1 or LBD/AF2 domain of ER $\alpha$ together with HA-tagged CITED1 and cultured for $24 \mathrm{~h}$ in the absence of hormones. Cells were then stimulated with $100 \mathrm{nM} 17 \beta$-estradiol (E2) or vehicle (ethanol) for $1 \mathrm{~h}$, followed by anti-FLAG immunoprecipitation. Coprecipitated HA-CITED1 was detected by anti-HA Western blotting (top). Expression of the transfected proteins was evaluated by anti-FLAG (for AF1 or AF2 domains) or anti-HA (for CITED1) Western blotting (bottom). (B) Transfected CITED1 interacts with endogenous ER $\alpha$ in an estrogen-dependent manner. MCF-7 cells were transfected with HA-tagged CITED1 and cultured for $24 \mathrm{~h}$ in the absence of hormones. Cells were then stimulated with $100 \mathrm{nM} 17 \beta$-estradiol (E2) or vehicle (ethanol) for $1 \mathrm{~h}$, followed by anti-HA immunoprecipitation. Coprecipitated ER $\alpha$ was detected by Western blotting using an anti-ER $\alpha$ antibody (top). Expression of proteins was evaluated by anti-HA (for transfected CITED1) or anti-ER $\alpha$ (for endogenous ER $\alpha$ ) Western blotting (bottom).

positive MCF-7 human breast cancer cells expressing or not expressing exogenous CITED1. As shown in Figure 7A, a moderate amount of CITED1 was expressed stably in MCF-7 cells infected by CITED1-expressing retrovirus, but cells infected with control virus expressed a very small amount of endogenous CITED1.

Using these retrovirus-infected MCF-7 cells, we attempted to determine whether the estrogen-induced interaction of $\mathrm{ER} \alpha$ with $\mathrm{p} 300$, a critical step of estrogeninduced transcription (Shang et al. 2000), is modulated by the presence of CITED1. Amounts of endogenous ER $\alpha$ and p300 proteins were not affected by the presence of
CITED1 (Fig. 7B, bottom). When cells were starved for estrogen, no ER $\alpha-\mathrm{p} 300$ interaction was detected by immunoprecipitation with or without CITED1. Remarkably, however, when cells were stimulated with $100 \mathrm{nM}$ $17 \beta$-estradiol, three to five times more p300 was coprecipitated with ER $\alpha$ from lysates of CITED1-expressing MCF-7 cells than lysates of control cells (Fig. 7B, top). These results strongly suggest that the estrogen-induced interaction of $\mathrm{ER} \alpha$ with $\mathrm{p} 300$ is stabilized when CITED1 is expressed in cells.

To examine whether CITED1 enhances cellular responses to estrogen, we determined whether expression of CITED1 in MCF-7 cells affects their estrogen-dependent growth. As shown in Figure 7C, CITED1-expressing MCF-7 cells grew significantly better than the control cells, especially when estrogen concentration in the culture medium was low. However, when cultured in the complete absence of estrogen, both CITED1-expressing and control cells grew only marginally, indicating that the growth-facilitating activity of CITED1 is dependent on the presence of estrogen. Therefore, CITED1 enhances estrogen-dependent growth of MCF-7 cells.

We next determined whether CITED1 affects estrogen-induced aggregation of MCF-7 cells /Olea et al. 1992). In the complete absence of estrogen, neither CITED1-expressing nor control cells showed significant
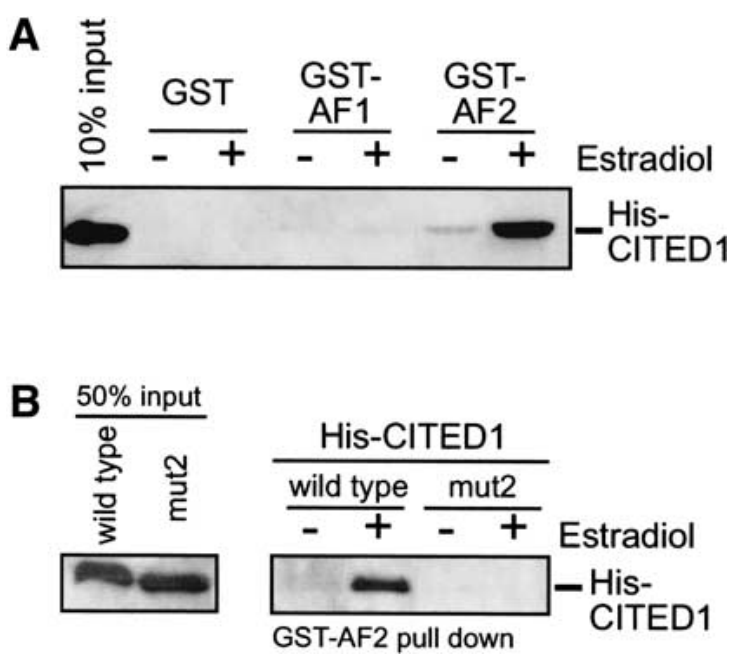

Figure 5. Direct binding of CITED1 to the LBD/AF2 domain of $\mathrm{ER} \alpha$ in vitro: GST pull-down assay. (A) Estrogen-dependent binding of CITED1 to ER $\alpha$. Equal amounts of GST or GSTfusion proteins of $\mathrm{ER} \alpha$ domains (AF1 or LBD/AF2) were immobilized on glutathione-conjugated Sepharose beads and incubated with polyhistidine epitope-tagged CITED1 (His-CITED1) in the presence or absence of $100 \mathrm{nM} \mathrm{17 \beta -estradiol.} \mathrm{After} \mathrm{ex-}$ tensive washing of the beads, coprecipitated CITED1 was detected by anti-His Western blotting. $(B)$ Loss of ER $\alpha$-binding activity of a function-dead CITED1 mutant. Equal amounts of GST-fusion LBD/AF2 of ER $\alpha$ were immobilized on beads and incubated with His-CITED1 or His-CITED1(mut2), a CITED1 mutant that does not enhance $\mathrm{ER} \alpha$-mediated transactivation (see Fig. 3), in the presence or absence of $100 \mathrm{nM} 17 \beta$-estradiol. After washing of the beads, coprecipitated CITED1 was detected by anti-His Western blotting. 


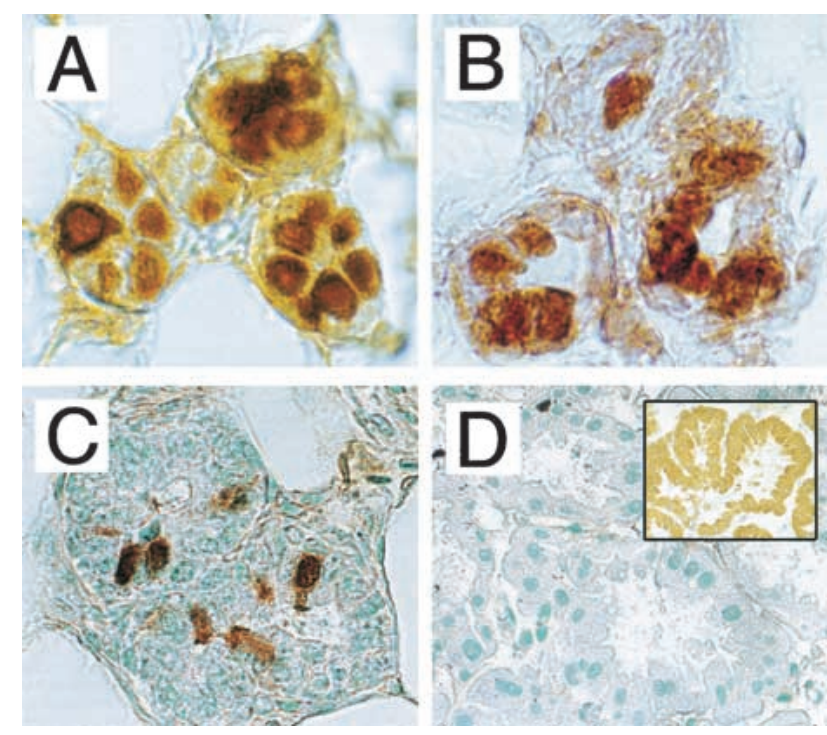

Figure 6. Expression of CITED1 and ER $\alpha$ in mouse mammary epithelial cells: immunohistochemistry. (A) Expression of CITED1 in 12-week-old nulliparous mammary epithelial cells. (B) Expression of ER $\alpha$ in the same specimen of panel $A .(C)$ Reduced expression of CITED1 in $11.5 \mathrm{dpc}$ pregnant mammary epithelial cells. (D) Absence of CITED1 expression in $11.5 \mathrm{~d}$ post-delivery lactating mammary epithelial cells. Insert shows strong nucleo-cytoplasmic staining by an anti-CITED4 antibody as a positive control.

aggregation (Fig. 7D, top). However, when a very low concentration ( $1 \mathrm{pM}$ ) of $17 \beta$-estradiol was added to the culture medium, CITED1-expressing cells showed marked aggregation, and control cells showed minimal morphological changes (Fig. 7D, middle). At a higher estrogen concentration (10 nM), both CITED1-expressing MCF-7 cells and control cells showed comparable amounts of aggregation (Fig. 7D, bottom). These results further showed that CITED1 enhances cellular sensitivity to estrogen.

CITED1 enhances estrogen-induced expression of the transforming growth factor- $\alpha$ mRNA transcript in MCF-7 cells

To further characterize effects of CITED1 expression in MCF-7 cells, we next attempted to determine whether expression of known estrogen target genes in this cell line is affected by CITED1. Thus, we compared amounts of the mRNA transcripts of selected estrogen-inducible genes between the CITED1-expressing and control MCF-7 cells after stimulation with estrogen using the semiquantitative reverse transcription-polymerase chain reaction (RT-PCR) technique as described previously (Shioda et al. 1997b). The estrogen-inducible genes analyzed included $\alpha-1$ antichymotrypsin; c-Fos; cdc25; Ha-Ras; progesterone receptor $(P R)$; PS2; transforming growth factor- $\alpha$ (TGF- $\alpha) ;$ BRCA1; cathepsin D; E2F1; HMG1; insulin receptor substrate-1; insulin receptor binding protein-4; $\mathrm{c}-\mathrm{Myc}$; and WISP-2. Interestingly, among these 15 genes tested, we could detect effects of CITED1 expression with only two genes-namely, estrogen-induced expression of the TGF- $\alpha$ mRNA transcript was significantly enhanced without changes in its basal expression level observed in the absence of estrogen, whereas both basal and estrogen-induced expression of the c-Myc mRNA transcript was significantly reduced (Fig. 8A,B). In our hands, we did not observe significant effects of CITED1 on basal or estrogen-induced expression of other estrogen-target genes (PR and pS2 data are shown in Fig. 8A,B; other data not shown). The enhancement of estrogen-induced expression of the TGF- $\alpha$ mRNA transcript by CITED1 was further confirmed by Northern blot hybridization (Fig. 8C,D). These results imply that CITED1 may coactivate endogenous ER-target genes in a gene-specific manner.

\section{CITED1 is recruited to the TGF- $\alpha$ promoter in an estrogen-dependent manner but not to the $\mathrm{pS} 2$ promoter}

To obtain insights into the molecular basis of the apparently gene-specific action of CITED1 on estrogen-target genes, and to determine whether CITED1 acts directly on the promoters of the endogenous ER target genes, we employed the chromatin immunoprecipitation (ChIP) assay and examined in vivo recruitment of CITED1 to the $p S 2$ and the TGF- $\alpha$ promoters in MCF-7 cells.

As shown in Figure 9, ER $\alpha$ was recruited to both the $p S 2$ and the TGF- $\alpha$ promoters in an estrogen-dependent manner. Judging from the quantitative aspects of increase in amounts of the PCR product after estrogen treatment (Fig. 9B, left), the estrogen-induced interaction of ER $\alpha$ with the TGF- $\alpha$ promoter appeared significantly weaker than the interaction of $\mathrm{ER} \alpha$ with the $p S 2$ promoter. This result was consistent with the fact that the TGF- $\alpha$ mRNA transcript was induced less strongly than the $p S 2$ mRNA transcript by estrogen in this cell line (Fig. 8A,B). Although we do not know exactly why ER $\alpha$ interacted with the TGF- $\alpha$ promoter less strongly than with the $p S 2$ promoter, this observation may reflect the difference in the structures of the estrogen responsive elements (EREs) of these promoters (see Discussion for more detail).

In contrast, although the estrogen-dependent recruitment of CITED1 to the TGF- $\alpha$ promoter was clearly shown by this assay, we did not detect any estrogendependent interaction of CITED1 with the $p S 2$ promoter (Fig. 9A,B, right). These results strongly suggest that CITED1 is recruited directly to a specific subset of the estrogen-inducible genes in a gene-specific manner and is involved in estrogen-dependent transcriptional coactivation. It should be noted that the binding of CITED1 to the TGF- $\alpha$ promoter was observed not only in MCF-7 cells infected by the CITED1-expressing retrovirus but also in the cells infected by the control virus, indicating that the endogenous CITED1, which was expressed in MCF-7 cells only weakly (Fig. 7A), was effectively recruited to the endogenous TGF- $\alpha$ promoter. 
Yahata et al.

A

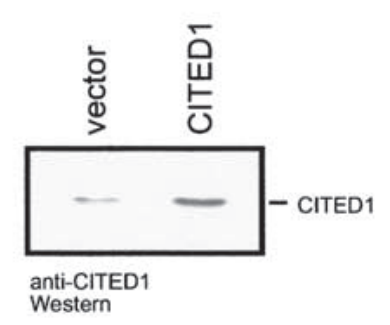

B

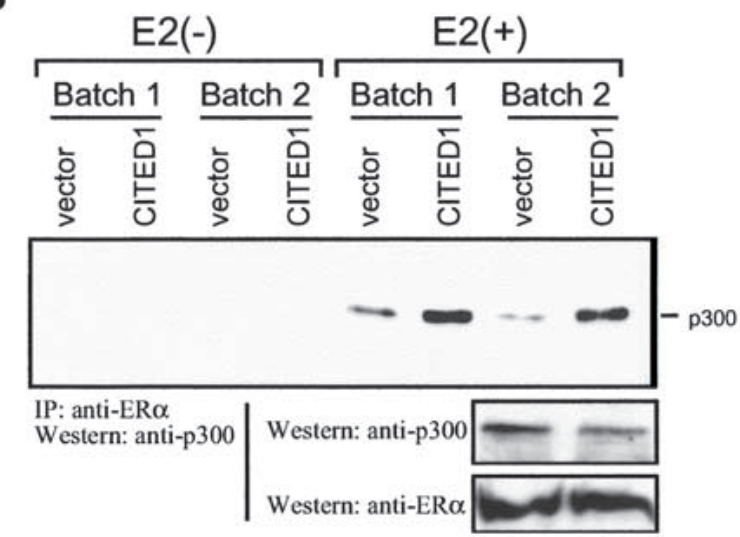

C

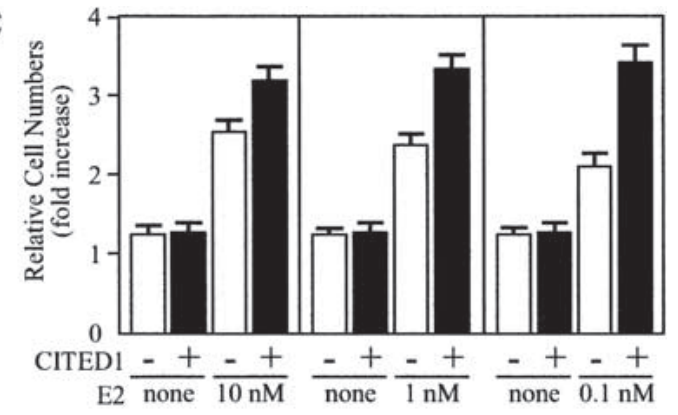

D

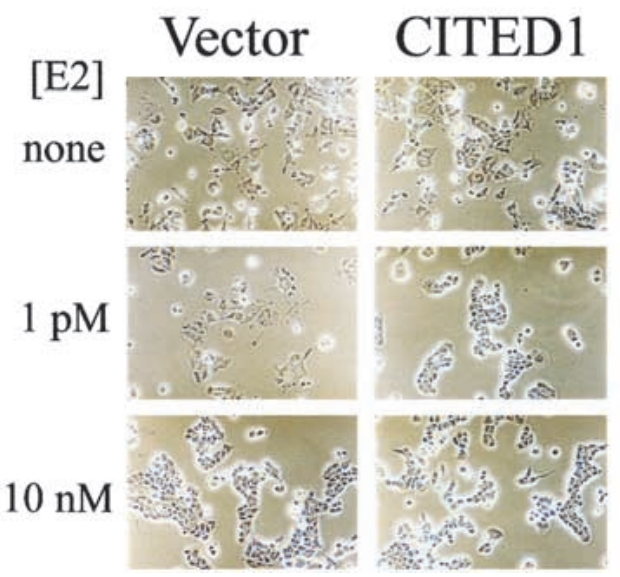

Figure 7. CITED1 enhances estrogen sensitivity of MCF-7 breast cancer cells. (A) Expression of CITED1 in MCF-7 cells by retrovirus transduction: anti-CITED1 Western blotting using monoclonal antibody 2H6. (B) Stabilization of estrogen-dependent interaction of $\mathrm{ER} \alpha$ and $\mathrm{p} 300$ by CITED1 in vivo. Two independent batches of MCF-7 cells infected by the CITED1-expressing retrovirus or vector were cultured in hormone-free medium for $16 \mathrm{~h}$ and then stimulated with $100 \mathrm{nM} 17 \beta$-estradiol [E2(+)] or vehicle [E2(-)] for $3 \mathrm{~h}$ followed by anti-ER $\alpha$ immunoprecipitation. Coprecipitated p300 was detected by anti-p300 Western blotting (top). Expression of endogenous p300 and ER $\alpha$ was evaluated by Western blotting of the cell lysates before immunoprecipitation (bottom). (C) Enhancement of estrogen-dependent growth of MCF-7 cells by CITED1. CITED1-expressing (filled bars) and control (open bars) MCF-7 cells were cultured in hormone-free medium for $2 \mathrm{~d}$. Equal numbers of cells were then inoculated to dishes and cultured for $8 \mathrm{~d}$ in the absence or presence of varying concentrations of $17 \beta$-estradiol (E2) followed by cell counting using a hemocytometer. Each datum represents the mean \pm SEM of fold increase in cell number over the inoculum size calculated from three independent cultures. $(D)$ Enhancement of estrogen-induced cell aggregation of MCF-7 cells by CITED1. Equal numbers of hormone-starved CITED1-expressing and control MCF-7 cells were inoculated to dishes and cultured in the presence of varying concentrations of 17 $\beta$-estradiol (E2) for 5 d. Phase contrast photographs of equal magnification $(\times 200)$ are shown.

\section{Discussion}

\section{CITED1 is a selective, agonist-dependent}

\section{ER coactivator}

In the present study we have provided biochemical and cell biological evidence that CITED1, and probably other members of the CITED family also, functions as an ER coactivator.

CITED1 (and other CITED proteins) enhanced estrogen-dependent transcription from synthetic promoters when analyzed by transfection-based assays (Figs. 1, 2). This coactivation was relatively selective to ER-mediated transcription, with far weaker effects on other NRs tested, and, importantly, all CITED proteins coactivated both ER $\alpha$ and ER $\beta$ with comparable efficiencies (Fig. 1B). The ER coactivation by CITED1 was strictly dependent on the presence of ER agonist; ER-binding estrogen antagonist or partial agonists failed to support this activity (Fig. 1B-D).
CITED1 was capable of coactivating endogenous ERs in a manner dependent on the core promoters located downstream of the EREs (Fig. 2). The 3.0-fold enhancement of EREtk-driven, estrogen-dependent transcription by CITED1 in MCF-7 cells was comparable to the strength of the reported coactivating activities of p300 ( fourfold; Chen et al. 1999) and AIB1 ( twofold; Anzick et al. 1997; Planas-Silva et al. 2001) for this promoter. Therefore, when evaluated by synthetic model promoters for ER-mediated transcription, CITED1 acted as an ER coactivator with moderate strength of the coactivating activity.

Biochemical analyses showed that CITED1 bound directly to the $\mathrm{LBD} / \mathrm{AF} 2$ domain of $\mathrm{ER} \alpha$ in vitro and in vivo in an estrogen-dependent manner (Figs. 4, 5). A CITED1 mutation substituting amino acids 157-158 (VL) with alanines resulted in a concomitant loss of both ER-coactivating activity (Fig. 3) and binding to ER $\alpha$ in vitro (Fig. $5 \mathrm{~B})$, suggesting that the ER coactivation by CITED1 re- 
A

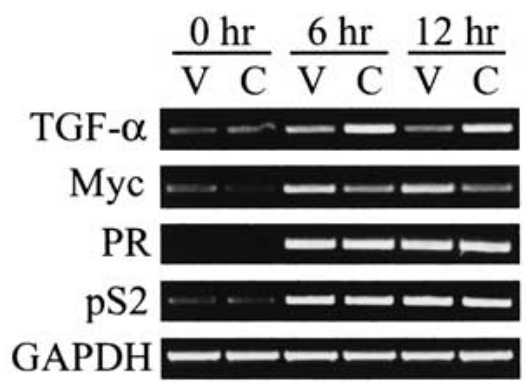

B
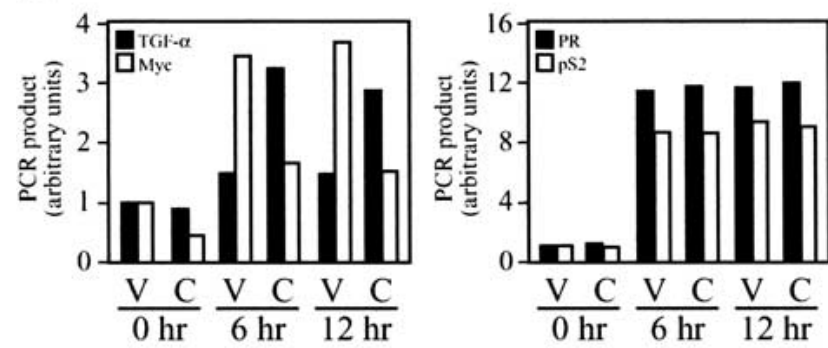

C
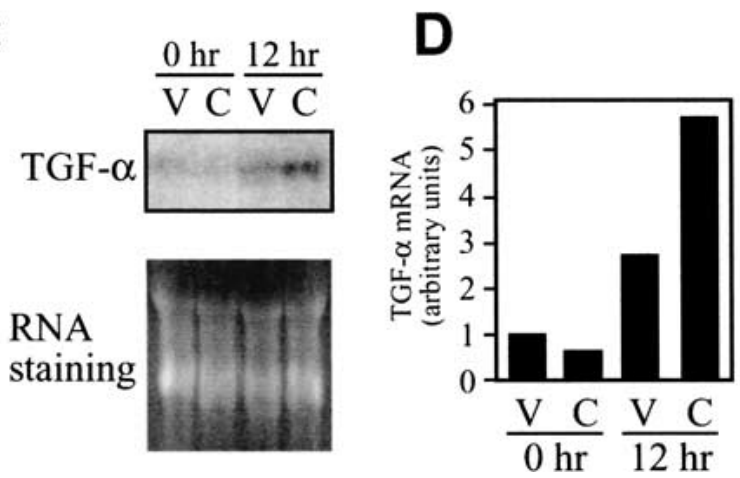

Figure 8. CITED1 enhances estrogen-dependent induction of the TGF- $\alpha$ mRNA transcript in MCF-7 breast cancer cells. $(A)$ Semiquantitative RT-PCR analysis of estrogen-inducible genes. MCF-7 cells infected with vector (V) or CITED1-expressing (C) retroviruses were cultured in hormone-free medium for $24 \mathrm{~h}$, followed by stimulation with $10 \mathrm{nM}$ of $17 \beta$-estradiol for indicated periods. Total RNA was then isolated and subjected to semiquantitative RT-PCR analysis of estrogen-inducible genes in the presence of $\left[\alpha_{-}{ }^{32} \mathrm{P}\right] \mathrm{dCTP}$. (PR) progesterone receptor; (GAPDH) glyceroaldehyde 3-phosphate dehydrogenase (a control gene not inducible by estrogen). (B) Quantitative representation of amounts of the mRNA transcripts analyzed in panel $A$. The bands of the radiolabeled PCR products were excised from gels (shown in $A$ ), and their radioactivity was counted by liquid scintillation. Calculated relative amounts of the PCR products normalized by the GAPDH amounts are shown. $(C)$ Northern blot analysis of estrogen-induced expression of the TGF- $\alpha$ mRNA transcript. The total RNA analyzed in panel $A$ (5 $\mu \mathrm{g}$ per lane) was subjected to Northern blot hybridization using a radiolabeled cDNA probe for human TGF- $\alpha$. Equal amounts of RNA loading were confirmed by RNA staining with ethidium bromide. (D) Quantitative representation of amounts of the TGF- $\alpha$ mRNA transcript analyzed in panel $C$ by densitometry.

quires its estrogen-dependent binding to ERs. Because ERs change their conformation in a ligand-dependent manner and recruit coactivators only when appropriate conformations are induced by estrogen agonists (Glass and Rosenfeld 2000), our data strongly suggest that CITED1 recognizes the precise "active form" conformations of ERs. This recognition is apparently selective to ERs, distinguishing them from other ligand-activated NRs.

CITED1 is coexpressed with ER $\alpha$ strongly in the nucleus of mammary epithelial cells of nulliparous female mice (Fig. 6). CITED1 was originally isolated based on its relatively strong expression in normal melanocytes, which are also direct targets of estrogen (Ranson et al. 1988; Maeda et al. 1996; Kippenberger et al. 1998). The tissue distribution of CITED1 in adult mice is therefore consistent with its possible biological roles in estrogen signaling. CITED1 enhanced estrogen sensitivity of MCF-7 cells when expressed by retrovirus transduction. CITED1 enhanced estrogen-dependent growth of MCF-7 cells, especially when concentrations of estrogen in culture medium were low (Fig. 7C), without affecting amounts of $E R \alpha$ or $p 300$ expression (Fig. 7B). MCF-7 cells expressing CITED1 aggregated in the presence of a very low concentration of estrogen, whereas control cells required much higher concentrations of estrogen to initiate aggregation (Fig. 7D).

In MCF-7 cells, CITED1 enhanced estrogen-induced expression of the TGF- $\alpha$ mRNA transcript, but it suppressed basal and estrogen-induced expression of the cMyc mRNA transcript (Fig. 8). However, in our hands, no significant influences of CITED1 on expression of other estrogen target genes (such as the progesterone receptor or $p S 2$ genes) were detected. These results suggest that, at least within the contexts of experimental conditions described in the present study, the effects of CITED1 appeared gene-specific. The dependency of the ER coactivation by CITED1 on the core promoter located downstream of the EREs in synthetic estrogen-dependent promoters (Fig. 2) may also support the concept that CITED1 functions as a gene-specific ER coactivator. A similar core promoter-dependent coactivation from synthetic estrogen-dependent promoters has been observed with SRC-1 and its isoforms (Kalkhoven et al. 1998). On the other hand, the reduction in estrogen-induced expression of the c-Myc mRNA transcript in the presence of exogenous CITED1 (Fig. 8A) may imply possible transcriptional suppression of the c-MYC promoter by CITED1. However, we cannot deny a possibility that this apparent reduction observed at $6 \sim 12 \mathrm{~h}$ after an addition of estrogen could reflects a very quick activation of the c-MYC gene followed by a sustained inactivation. Elucidating possible biological significance and mechanisms of actions of the (core) promoter-dependent ER coregulation by CITED1 awaits future studies.

The observation that endogenous CITED1 was recruited to the endogenous $T G F-\alpha$ promoter but not to the pS2 promoter in an estrogen-dependent manner in MCF-7 cells (Fig. 9) suggests that the apparent gene-specific action of CITED1 may be attributed to its promoterspecific recruitment. Interestingly, the estrogen-dependent interaction of $\mathrm{ER} \alpha$ with the TGF- $\alpha$ promoter DNA 
Yahata et al.

Figure 9. CITED1 is recruited to the $T G F-\alpha$ promoter in an estrogen-dependent manner but not to the $p S 2$ promoter. In vivo binding of ER $\alpha$ or CITED1 to either the $p S 2$ promoter or the TGF- $\alpha$ promoter was examined by chromatin immunoprecipitation (ChIP) assay. (A) MCF-7 cells infected with vector or CITED1-expressing retroviruses were treated with $(+)$ or without (-) $100 \mathrm{nM} 17 \beta$-estradiol (E2) for 45 min and fixed immediately by formaldehyde. Soluble chromatin was prepared from the fixed cells by sonication followed by density-gradient centrifugation and subjected to immunoprecipitation using anti-ER $\alpha$ or anti-CITED1 antibodies. Coprecipitated genomic DNA was released from the cross-linked protein by heat and then amplified by polymerase chain reaction (PCR) using primers that annealed to the proximal region of the $p S 2$ or TGF- $\alpha$ promoters. Positions of the PCR primers are indicated by pairs of arrows in the diagrams of each promoter; the transcriptional initiation site is defined as nucleotide number 1 . The presence of the $p S 2$ and TGF- $\alpha$ promoter DNA in the chromatin preparations before immunoprecipitation was confirmed by PCR (Input). (B) Quantitative aspects of recruitment of ER $\alpha$ and CITED1 to the $p S 2$ and TGF- $\alpha$ promoters. Signal intensities of the PCR products shown in panel $A$ were quantitated by densitometry and expressed as proportion of input.

appeared weaker than the interaction between $\mathrm{ER} \alpha$ and the $p S 2$ promoter DNA (Fig. 9A,B, left). This phenomenon might account for the fact that the TGF- $\alpha$ mRNA transcript was induced less strongly than the $p S 2$ mRNA transcript by estrogen in this cell line (Fig. 8A,B). The $p S 2$ proximal promoter contains a nearly perfect ERE (GGTCAcggTGGCC; bold indicates deviation from the consensus sequence), which differs from the ideal consensus sequence of the ERE found in the vitellogenin A2 promoter (GGTCAnnnTGACC) by only one nucleotide (Berry et al. 1989). On the other hand, the TGF- $\alpha$ proximal promoter contains a 53-bp sequence that binds to liganded ER $\alpha$ in vitro and is functionally sufficient to activate transcription of reporter genes in an estrogendependent manner when evaluated by a transfectionbased assay (El-Ashry et al. 1996). This 53-bp sequence contains two imperfect but functional EREs, GGATCccaGGTCG and GGTGCgctCAGCG, which deviate significantly from the consensus sequence. Because the binding affinity of EREs to ER $\alpha$ decreases along with accumulation of deviations from the consensus sequence (Nardulli et al. 1996), the binding affinity of EREs found in the TGF- $\alpha$ promoter to $E R \alpha$ may be significantly lower than that of the nearly perfect ERE found in the $p S 2$ promoter, possibly accounting for the observed weaker interaction of the former EREs with liganded $\mathrm{ER} \alpha$ compared to the latter (Fig. 9A,B, left). It is tempting to speculate that the binding of ER $\alpha$ to the suboptimal ERE sequences found in the TGF- $\alpha$ promoter might affect conformation of the DNA-bound ER $\alpha$; it could also affect composition and/or configuration of the transcriptional protein complex formed around the DNA-bound $\mathrm{ER} \alpha$. Therefore, characterization of the differences in the molecular basis of ER $\alpha$-mediated transcriptional activation between the TGF- $\alpha$ and $p S 2$ promoters might provide insights into the mechanism of the gene-specific recruitment of CITED1.

CITED1 binds directly to ER $\alpha$ in an estrogen-dependent manner but lacks the canonical LXXLL NR-binding signature motif

Nearly all coactivators that have been cloned using their ligand-dependent NR-binding activity contain the LXXLL NR-binding signature motif (Glass and Rosenfeld 2000). Together with adjacent amino acids, the LXXLL sequence forms a short $\alpha$-helix that docks to a hydrophobic cleft on the surface of the LBD of NRs. Binding of cognate ligands to NRs induces conformational changes in the LBD so that the binding of the LXXLL helix to the LBD is stabilized by the AF2 domain. Surprisingly, however, CITED1 (and other CITED proteins) does not contain the canonical LXXLL motif (Yahata et al. 1996), despite the fact that it binds directly to the LBD/AF2 domain of ER $\alpha$ in an estrogen-dependent manner (Fig. 5A). Although the $\mathrm{N}$-terminal sequence of the CR2 domain of CITED1 was necessary for this binding (Fig. 5B), it varies significantly from the LXXLL motif (Fig. 3A). Therefore, the binding of CITED1 to ER seems to use a unique mechanism. Interestingly, according to computer-aided prediction of the secondary structures around the $\mathrm{N}$-ter- 
minal region of the CR2 domain of CITED1, this region is highly likely to form a short $\alpha$-helix, which is a common feature of all the CITED proteins (K.R. Coser and T. Shioda, unpubl.). This $\alpha$-helix might resemble the LXXLL helix to some extent in terms of the space-filling structures and could bind to the LBD of ERs in a manner similar to the LXXLL-containing coactivators although the LBDs of other NRs do not accept it. The observation that NRIF3 interacts selectively with thyroid hormone receptor and retinoid X receptor through the LXXIL sequence, a variant form of the LXXLL motif (Li et al. 1999|, may support this speculation. Determination of the precise structural basis of the interaction between the ER-binding $\alpha$-helix of the CITED proteins and ERs may provide useful information regarding the variation from the canonical LXXLL motif and selective interaction with a subset of NRs.

Possible biochemical mechanisms of the enhancement of estrogen-dependent transcription by CITED1

$\mathrm{CBP} / \mathrm{p} 300$ histone acetyltransferases are recruited to ERdependent promoters when cells are stimulated by estrogen (Shang et al. 2000) and play critical roles in activation of ER-mediated transcription (Chakravarti et al. 1996; Kraus and Kadonaga 1998), forming multiprotein complexes involving ERs, the p160 coactivators, and pCAF (Freedman 1999). CITED1 binds directly to CBP/ p300 (Yahata et al. 1996) and ER $\alpha$ (Figs. 4, 5) through distinct regions located within the conserved CR2 domain (Fig. 3). CITED1 effectively coactivated ER $\alpha$-mediated transcription, which was further augmented synergistically by exogenous p300 (Fig. 1E). The estrogen-dependent physical interaction between ER $\alpha$ and p300 seemed stabilized when cells expressed CITED1 (Fig. 7B). Taken together, these results suggest that CITED1 coactivates ER-mediated transcription through enhancing roles of $\mathrm{CBP} / \mathrm{p} 300$ in this event. Because the histone acetyltransferase activity of $\mathrm{CBP} / \mathrm{p} 300$ is critical for its ER-coactivating activity (Kraus and Kadonaga 1998; Chen et al. 1999), it is an interesting question whether CITED1 affects histone acetylation of chromatin at ERdependent promoters. Previously reported SMAD-coactivating activity of CITED1 observed by transfectionbased assays was also dependent on CBP/p300 (Shioda et al. 1998; Yahata et al. 2000) and, therefore, might involve similar mechanisms.

The facts that CITED1 binds directly to both ER $\alpha$ (Fig. 5) and CBP/p300 (Yahata et al. 2000) through discrete regions (Figs. 3, 5) and that the estrogen-dependent binding of ER $\alpha$ to p300 seems stabilized in CITED1-expressing MCF-7 cells (Fig. 7B) may support a speculation that CITED1, ERs, and CBP/p300 could form a ternary protein complex. However, attempts to show such a ternary complex by biochemical analyses have not been successful in our laboratory. This may be owing to technical difficulties in demonstrating formation of stable multiprotein complexes involving NRs and more than one coactivator by biochemical approaches such as sequential immunoprecipitation. In another interpretation, the difficulty in demonstrating stable protein complexes simul- taneously involving $\mathrm{CBP} / \mathrm{p} 300, \mathrm{ER} \alpha$, and CITED1 might be attributed to the dynamic and transient nature of the estrogen-induced interaction between ERs and the coactivators (Chen et al. 1999; Shang et al. 2000). The observed stabilized interaction between ER $\alpha$ and p300 might be a consequence of transient interaction of CITED1 with these proteins and could involve protein modifications, but it may not necessarily require physical and stable contact of CITED1 with them. Further studies are required to elucidate the molecular mechanism of this phenomenon.

\section{Possible biological roles of CITED1 as an estrogen sensitivity enhancer}

Because transcriptional activation by ERs is dependent on cell type and ERE-containing promoters (Tora et al. 1989; Berry et al. 1990), the existence of cell- and/or gene-specific ER coactivators has been speculated. The CITED proteins are expressed in embryos as well as adult vertebrates in cell- and stage-specific manners (Shioda et al. 1996; Dunwoodie et al. 1998; Andrews et al. 2000), and the ER-coactivating activity of CITED1 is apparently gene-specific (Figs. 2, 8), leading to the speculation that expression of each member of the CITED proteins might contribute to determination of cell- and gene-specific sensitivity to estrogen.

The observation that CITED1 protein is expressed strongly in nulliparous mouse mammary epithelial cells but is rapidly lost with pregnancy (Fig. 6) may imply roles of CITED1 in this tissue. Because the extensive growth of the mammary ductal structure during puberty is estrogen-dependent, CITED1 could contribute to this phenomenon by enhancing the sensitivity of mammary epithelial cells to estrogen when the concentration of circulating estrogen is low. Our observation that the ability of CITED1 to enhance estrogen-dependent growth of MCF-7 breast cancer cells was more apparent when cells were cultured in relatively low concentrations of estrogen than in higher concentrations of estrogen (Fig. 7C) may support this hypothesis. Increased estrogen sensitivity of CITED1-expressing MCF-7 cells has also been shown by evaluating their estrogen-dependent aggregation (Fig. 7D). The role of TGF- $\alpha$ as an estrogeninduced autocrine growth factor for human breast cancer cells has been shown previously (Bates et al. 1988; Kenney et al. 1993). Therefore, the enhancement of estrogeninduced expression of TGF- $\alpha$ by CITED1 (Fig. 8) may account, at least partly, for the ability of CITED1 to enhance estrogen-dependent growth of MCF-7 cells.

In summary, we have provided evidence that CITED1 functions as a selective ER coactivator. We also proposed possible roles of CITED1, and other CITED proteins as well, as cell- and gene-specific modulators of ER-mediated gene expression.

\section{Materials and methods}

Cell culture, transfection, and reporter assay

MCF-7 human breast cancer cells and COS-1 cells were purchased from American Type Culture Collection and maintained 
as described (Yahata et al. 2000). For hormone-free culture, phenol red-free Dulbeccos's modified minimum essential medium (DMEM) supplemented with $10 \%$ charcoal/dextran-treated fetal calf serum (HyClone) was used. Transfection and luciferase reporter assays were performed as described (Yahata et al. 2000); each datum represents the mean of at least three independent experiments.

\section{Retrovirus transduction}

Dualotropic LNCX (control) and LNCX-CITED1 (CITED1-expressing) retroviruses were generated by inserting human CITED1 cDNA into the multiple cloning site of the pLNCX vector and transfecting into Retropack PT67 packaging cells (Clontech). To establish CITED1-expressing MCF-7 cells, cells were infected by the LNCX-CITED1 and LNCX viruses, followed by G418 selection. One batch of infection generated more than 100 independent G418-resistant clones, which were pooled before experiments. Reproducibility of experiments using the retrovirus-infected cells was confirmed using at least two independent batches of infected cells.

\section{Plasmids}

Mammalian expression plasmids for hemagglutinin (HA) epitope-tagged human CITED1 and CITED2 were described (Yahata et al. 2000), and plasmids for HA-tagged chick CITED3 (Andrews et al. 2000) and mouse CITED4 (Yahata et al. 2000) were constructed similarly. The plasmid for HA-tagged p300 was a gift from D.M. Livingston (Eckner et al. 1994). The plasmids for GAL4DBD fusion nuclear receptors and full-length human ER $\alpha$ are described in Kobayashi et al. (2000). The plasmids for the FLAG-epitope-tagged AF1 or AF2 domain of ER $\alpha$ were constructed using a PCR-based standard protocol and confirmed by sequencing. Luciferase reporter plasmids pERE-tk-Luc (White et al. 1994) and p3XERE-E1bTATA-Luc (Kalkhoven et al. 1998) were gifts from M.G. Parker. A GAL4-dependent luciferase reporter plasmid pGLUC8 was constructed by inserting eight tandem repeats of GAL4-binding elements into a pGV-B2 luciferase reporter vector (Tokyo Ink) prior to the E1B TATA box. Bacterial expression plasmids for the glutathione $S$-transferase (GST) fusion ER $\alpha$ domains are described in Endoh et al. (1999).

\section{Antibodies, immunoprecipitation, Western blotting, and immunohistochemistry}

Anti-CITED1 rabbit polyclonal antibody was described previously (Li et al. 1998). An anti-CITED1 mouse monoclonal antibody (clone 2H6) was generated against the full-length CITED1 protein and affinity-purified. Anti-CITED4 rabbit polyclonal antibody was generated against a synthetic peptide corresponding to the C-terminal end of mouse CITED4. Anti-HA monoclonal antibody (12CA5) was purchased from Roche Molecular Biochemicals; anti-FLAG monoclonal antibody (M2) was from Sigma; and anti-His (H-15), anti-ER $\alpha$ (sc-786), and anti-p300 (N15) antibodies were from Santa Cruz Biotechnology. For transfection-based coimmunoprecipitation assays, cells $\left(1 \times 10^{6}\right.$ per 6 -cm dish) were transfected with expression plasmids and cultured for $24 \mathrm{~h}$ in hormone-free medium, followed by stimulation with hormones. Cells were then lysed in IP buffer $(50 \mathrm{mM}$ Hepes/ $\mathrm{NaOH}$ at $\mathrm{pH} 7.5,120 \mathrm{mM} \mathrm{NaCl}, 2.5 \mathrm{mM}$ EGTA, $1 \mathrm{mM}$ EDTA, $1 \mathrm{mM}$ dithiothreitol, $10 \%$ glycerol, $0.5 \%$ NP-40) supplemented with phosphatase inhibitors $150 \mathrm{mM}$ sodium fluoride, $25 \mathrm{mM}$ sodium glycerophosphate, $1 \mathrm{mM}$ orthovanadate) and proteinase inhibitors (10 $\mu \mathrm{g} / \mathrm{mL}$ aprotinin, $10 \mu \mathrm{g} / \mathrm{mL}$ leupeptin).
Immunoprecipitation and Western blotting were performed as described (Yahata et al. 2000). Preparation of histological slides and immunohistochemical staining were performed as described using anti-CITED1 polyclonal antibody (Li et al. 1998) and anti-ER $\alpha$ (sc-786) antibody.

\section{In vitro protein binding assay}

Polyhistidine epitope-tagged human CITED1 (His-CITED1) and its mutant were expressed in Sf9 insect cells using recombinant baculoviruses and purified to homogeneity using a metal chelating column (Yahata et al. 2000). Glutathione S-transferase (GST) fusion proteins of the AF1 or LBD/AF2 domain of ER $\alpha$ (GST-AF1 and GST-AF2) were expressed in Escherichia coli and purified by glutathione-conjugated Sepharose beads (Amersham). For the GST pull-down assay, His-CITED1 or its mutant was incubated with GST, GST-AF1, or GST-AF2 immobilized on glutathione-conjugated Sepharose beads in binding buffer $(20$ $\mathrm{mM}$ Tris/ $\mathrm{HCl}$ at $\mathrm{pH} 7.5,100 \mathrm{mM} \mathrm{NaCl}, 1 \mathrm{mM}$ EDTA, $0.1 \%$ $\mathrm{NP}-40$ ) at $4^{\circ} \mathrm{C}$ for $2 \mathrm{~h}$ in the presence or absence of $100 \mathrm{nM}$ $17 \beta$-estradiol. Beads were then washed four times with the binding buffer and boiled in SDS-PAGE loading buffer for $5 \mathrm{~min}$. His-CITED1 or its mutant that bound to the GST fusion proteins was detected by anti-His Western blotting.

\section{RT-PCR and Northern blotting}

Total RNA was isolated from MCF-7 cultures using the RNeasy kit (QIAGEN) following manufacturer's instructions. Equal amounts of total RNA (100 ng per reaction) were subjected to semiquantitative RT-PCR analysis in the presence of $\left[\alpha-{ }^{32} \mathrm{P}\right] \mathrm{dCTP}$ as described previously (Shioda et al. 1997b). Primer sequences and detailed PCR conditions are available upon request. For Northern blot hybridization of the TGF- $\alpha$ mRNA transcript, $5 \mu \mathrm{g}$ per lane of total RNA was separated by $1 \%$ formaldehyde agarose gel electrophoresis, transferred to nylon membrane, and hybridized with the radiolabeled RT-PCR product of human TGF- $\alpha$ as described previously (Shioda et al. 1994). Amounts of the TGF- $\alpha$ mRNA transcript were quantified by densitometry of the radioactive bands on the X-ray films.

\section{Chromatin immunoprecipitation (ChIP) assay}

MCF-7 cells infected with vector- or CITED1-expressing retroviruses were cultured under hormone-free conditions for $3 \mathrm{~d}$. Cells were then treated with or without $100 \mathrm{nM} 17 \beta$-estradiol for $45 \mathrm{~min}$. Following treatment, cells were washed with PBS and cross-linked with $1 \%$ formaldehyde at $37^{\circ} \mathrm{C}$ for $10 \mathrm{~min}$, then rinsed with ice-cold PBS and collected into PBS containing protease inhibitors. After centrifugation, cell pellets were resuspended in lysis buffer (1\% SDS, 10 mM EDTA, 50 mM Tris-HCl at $\mathrm{pH} 8.1,1 \times$ protease inhibitor cocktail; Roche Molecular Biochemicals) and sonicated, followed by centrifugation to remove insoluble material. Supernatants were diluted in dilution buffer (1\% Triton X-100, 2 mM EDTA, $150 \mathrm{mM} \mathrm{NaCl}, 20 \mathrm{mM}$ Tris$\mathrm{HCl}$ at $\mathrm{pH} 8.1,1 \times$ protease inhibitor cocktail) and precleared at $4^{\circ} \mathrm{C}$ for $2 \mathrm{~h}$ with $2 \mu \mathrm{g}$ of sheared salmon sperm DNA, $20 \mu \mathrm{L}$ of normal mouse pr rabbit serum, and $45 \mu \mathrm{L}$ of protein A-sepharose (50\% slurry in $10 \mathrm{mM}$ Tris- $\mathrm{HCl}$ at $\mathrm{pH} 8.1,1 \mathrm{mM}$ EDTA). To the precleared lysate, antibodies against $\mathrm{ER} \alpha$, or CITED1 were added, and the reaction was incubated for $6 \mathrm{~h}$ to overnight, followed by an addition of $45 \mu \mathrm{L}$ of protein A-sepharose and a further incubation for $1 \mathrm{~h}$. Sepharose beads were then collected and washed sequentially for $10 \mathrm{~min}$ each in TSE I $0.1 \%$ SDS, $1 \%$ Triton $\mathrm{X}-100,2 \mathrm{mM}$ EDTA, $20 \mathrm{mM}$ Tris- $\mathrm{HCl}$ at $\mathrm{pH} 8.1,150$ $\mathrm{mM} \mathrm{NaCl})$, TSE II (0.1\% SDS, $1 \%$ Triton X-100, 2 mM EDTA, 
$20 \mathrm{mM}$ Tris- $\mathrm{HCl}$ at $\mathrm{pH} 8.1,500 \mathrm{mM} \mathrm{NaCl})$, and buffer III $(0.25$ M LiCl, 1\% NP-40, 1\% deoxycholate, 1 mM EDTA, $10 \mathrm{mM}$ Tris- $\mathrm{HCl}$ at $\mathrm{pH} 8.1$ ). Beads were then washed once with TE buffer and extracted with $100 \mu \mathrm{L}$ of $1 \%$ SDS-0.1 $\mathrm{M} \mathrm{NaHCO}_{3}$. Eluate was heated at $65^{\circ} \mathrm{C}$ overnight to reverse the formaldehyde cross-linking. DNA fragments were then purified from the eluate using a DNA purification kit (QIAquick spin, QIAGEN) and amplified by PCR using pairs of 20-mer primers: $p S 2$ sense, GGCCATCTCTCACTATGAATCACTTCTGC; $p S 2$ antisense, GGCAGGCTCTGTTTGCTTAAAGAGCG; TGF- $\alpha$ sense, GT CTGAAGTCAGGCGCTTCCTGCC; TGF- $\alpha$ antisense, GAAA AAGACGCAGACTAGGCAGGGC. The annealing positions of these primers are indicated in Figure 9.

\section{Acknowledgments}

We thank A. Kung, D.M. Livingston, and M.G. Parker for plasmids. We also thank M. Toft and J. Chesnes for technical help. We are grateful to Anita B. Roberts and David E. Fisher for their critical comments and useful discussion. This study was supported by grants RO1-CA82230 from the National Cancer Institute and the AVON Project on Breast Cancer fund to T.S.; RO1-CA57374 from the National Cancer Institute and an Academic Award DAMD17-99-1-9161 from the U.S. Department of Defense Breast Cancer Research Program to M.B.; and a fund from Massachusetts Breast Cancer Research Program to W.S.

The publication costs of this article were defrayed in part by payment of page charges. This article must therefore be hereby marked "advertisement" in accordance with 18 USC section 1734 solely to indicate this fact.

\section{References}

Andrews, J., O'Neill, M., Binder, M., Shioda, T., and Sinclair, A. 2000. Isolation and expression of a novel member of the CITED family. Mech. Dev. 95: 305-308.

Anzick, S.L., Kononen, J., Walker, R.L., Azorsa, D.O., Tanner, M.M., Guan, X.Y., Sauter, G., Kallioniemi, O.P., Trent, J.M., and Meltzer, P.S. 1997. AIB1, a steroid receptor coactivator amplified in breast and ovarian cancer. Science 277: 965 968.

Bates, S.E., Davidson, N.E., Valverius, E.M., Freter, C.E., Dickson, R.B., Tam, J.P., Kudlow, J.E., Lippman, M.E., and Salomon, D.S. 1988. Expression of transforming growth factor $\alpha$ and its messenger ribonucleic acid in human breast cancer: Its regulation by estrogen and its possible functional significance. Mol. Endocrinol. 2: 543-555.

Berry, M., Nunez, A.M., and Chambon, P. 1989. Estrogen-responsive element of the human $p S 2$ gene is an imperfectly palindromic sequence. Proc. Nat1. Acad. Sci. 86: 1218-1222.

Berry, M., Metzger, D., and Chambon, P. 1990. Role of the two activating domains of the oestrogen receptor in the cell-type and promoter-context dependent agonistic activity of the anti-oestrogen 4-hydroxytamoxifen. EMBO J. 9: 2811-2818.

Bhattacharya, S., Michels, C., Leung, M.-K., Arany, Z., Kung, A., and Livingston, D. 1999. Functional role of p35srj, a novel p300/CBP binding protein, during transactivation by HIF-1. Genes \& Dev. 13: 64-75.

Chakravarti, D., LaMorte, V.J., Nelson, M.C., Nakajima, T., Schulman, I.G., Juguilon, H., Montminy, M., and Evans, R.M. 1996. Role of CBP/p300 in nuclear receptor signalling. Nature 383: 99-103.

Chen, H., Lin, R.J., Xie, W., Wilpitz, D., and Evans, R.M. 1999. Regulation of hormone-induced histone hyperacetylation and gene activation via acetylation of an acetylase. Cell 98: 675-686.

Dunwoodie, S.L., Rodriguez, T., and Beddington, R.S.P. 1998. Msg1 and Mrg1, founding members of a gene family, show distinct pattern of gene expression during mouse embryogenesis. Mech. Dev. 72: 27-40.

Eckner, R., Ewen, M.E., Newsome, D., Gerdes, M., DeCaprio, J.A., Lawrence, J.B., and Livingston, D.M. 1994. Molecular cloning and functional analysis of the adenovirus E1A-associated $300-\mathrm{kD}$ protein $(\mathrm{p} 300)$ reveals a protein with properties of a transcriptional adaptor. Genes \& Dev. 8: 869-884.

El-Ashry, D., Chrysogelos, S.A., Lippman, M.E., and Kern, F.G. 1996. Estrogen induction of TGF- $\alpha$ is mediated by an estrogen response element composed of two imperfect palindromes. J. Steroid Biochem. Mol. Biol. 59: 261-269.

Endoh, H., Maruyama, K., Masuhiro, Y., Kobayashi, Y., Goto, M., Tai, H., Yanagisawa, J., Metzger, D., Hashimoto, S., and Kato, S. 1999. Purification and identification of p68 RNA helicase acting as a transcriptional coactivator specific for the activation function 1 of human estrogen receptor $\alpha$. Mol. Cell. Biol. 19: 5363-5372.

Fenner, M.H., Parrish, J.E., Boyd, Y., Reed, V., MacDonald, M., Nelson, D.L., Isselbacher, K.J., and Shioda, T. 1998. MSG1 (Melanocyte-Specific Gene 1): Mapping to chromosome Xq13.1, genomic organization and promoter analysis. Genomics 51: 401-407.

Freedman, L. 1999. Increasing complexity of coactivation in nuclear receptor signaling. Cell 97: 5-8.

Glass, C. and Rosenfeld, M. 2000. The coregulator exchange in transcriptional functions of nuclear receptors. Genes \& Dev. 14: $121-141$.

Glenn, D.J. and Maurer, R.A. 1999. MRG1 binds to the LIM domain of Lhx2 and may function as a coactivator to stimulate glycoprotein hormone $\alpha$-subunit gene expression. J. Biol. Chem. 274: 36159-36167.

Kalkhoven, E., Valentine, J.E., Heery, D.M., and Parker, M.G. 1998. Isoforms of steroid receptor co-activator 1 differ in their ability to potentiate transcription by the oestrogen receptor. EMBO I. 17: 232-243.

Kenney, N.J., Saeki, T., Gottardis, M., Kim, N., Garcia-Morales, P., Martin, M.B., Normanno, N., Ciardiello, F., Day, A., Cutler, M.L., et al. 1993. Expression of transforming growth factor $\alpha$ antisense mRNA inhibits the estrogen-induced production of TGF $\alpha$ and estrogen-induced proliferation of estrogenresponsive human breast cancer cells. I. Cell Physiol. 156: $497-514$.

Kippenberger, S., Loitsch, S., Solano, F., Bernd, A., and Kaufmann, R. 1998. Quantification of tyrosinase, TRP-1, and Trp-2 transcripts in human melanocytes by reverse transcriptase-competitive multiplex PCR-Regulation by steroid hormones. J. Invest. Dermatol. 110: 364-367.

Kobayashi, Y., Kitamoto, T., Masuhiro, Y., Watanabe, M., Kase, T., Metzger, D., Yanagisawa, J., and Kato, S. 2000. p300 mediates functional synergism between AF-1 and AF-2 of estrogen receptor $\alpha$ and $\beta$ by interacting directly with the $\mathrm{N}$ terminal A/B domains. J. Biol. Chem. 275: 15645-15651.

Kraus, W.L. and Kadonaga, J.T. 1998. p300 and estrogen receptor cooperatively activate transcription via differential enhancement of initiation and reinitiation. Genes \& Dev. 12: 331342.

Li, D., Desai-Yajnik, V., Lo, E., Schapira, M., Abagyan, R., and Samuels, H.H. 1999. NRIF3 is a novel coactivator mediating functional specificity of nuclear hormone receptors. Mol. Cell. Biol. 19: 7191-7202.

Li, H., Ahmed, N.U., Fenner, M.H., Ueda, M., Isselbacher, K.J., and Shioda, T. 1998. Regulation of expression of MSG1 me- 
Yahata et al.

lanocyte-specific nuclear protein in human melanocytes and melanoma cells. Exp. Cell Res. 242: 478-486.

Maeda, K., Naganuma, M., Fukuda, M., Matsunaga, J., and Tomita, Y. 1996. Effect of pituitary and ovarian hormones on human melanocytes in vitro. Pigment Cell Res. 9: 204-212.

Nardulli, A.M., Romine, L.E., Carpo, C., Greene, G.L., and Rainish, B. 1996. Estrogen receptor affinity and location of consensus and imperfect estrogen response elements influence transcription activation of simplified promoters. Mol. Endocrinol. 10: 694-704.

Olea, N., Villalobos, M., Ruiz de Almodovar, J.M., and Pedraza, V. 1992. MCF-7 breast cancer cells grown as multicellular spheroids in vitro: Effect of $17 \beta$-estradiol. Int. J. Cancer 50: 112-117.

Planas-Silva, M.D., Shang, Y., Donaher, J.L., Brown, M., and Weinberg, R.A. 2001. AIB1 enhances estrogen-dependent induction of cyclin D1 expression. Cancer Res. 61: 3858-3862.

Ranson, M., Posen, S., and Mason, R.S. 1988. Human melanocytes as a target tissue for hormones: In vitro studies with 1 $\alpha$-25, dihydroxyvitamin D3, $\alpha$-melanocyte stimulating hormone, and $\beta$-estradiol. J. Invest. Dermatol. 91: 593-598.

Schlange, T., Andree, B., Arnold, H., and Brand, T. 2000. Expression analysis of the chicken homologue of CITED2 during early stages of embryonic development. Mech. Dev. 98: 157160.

Shang, Y., Hu, X., DiRenzo, J., Lazar, M.A., and Brown, M. 2000. Cofactor dynamics and sufficiency in estrogen receptorregulated transcription. Cell 103: $843-852$.

Shioda, T., Ohta, T., Isselbacher, K.J., and Rhoads, D.B. 1994. Differentiation-dependent expression of the $\mathrm{Na}^{+} /$glucose cotransporter (SGLT1) in LLC-PK1 cells: Role of protein kinase $\mathrm{C}$ activation and on-going transcription. Proc. Natl. Acad. Sci. 91: 11919-11923.

Shioda, T., Fenner, M.H., and Isselbacher, K.J. 1996. msg1, a novel melanocyte-specific gene, encodes a nuclear protein and is associated with pigmentation. Proc. Natl. Acad. Sci. 93: $12298-12303$

Shioda, T., Fenner, M.H., and Isselbacher, K.J. 1997a. MSG1 and its related protein MRG1 share a transcription activating domain. Gene 204: 235-241.

Shioda, T., Munn, L., Fenner, M., Jain, R., and Isselbacher, K. 1997b. Early events of metastasis in the microcirculation involve changes in gene expression of cancer cells: Tracking mRNA levels of metastasizing cancer cells in the chick embryo chorioallantoic membrane. Am. J. Pathol. 150: 20992112.

Shioda, T., Lechleider, R.J., Dunwoodie, S.L., Li, H., Yahata, T., de Caestecker, M.P., Fenner, M.H., Roberts, A.B., and Isselbacher, K.J. 1998. Transcriptional activating activity of Smad4: Roles of SMAD hetero-oliogmerization and enhancement by an associating transactivator. Proc. Natl. Acad. Sci. 95: 9785-9790.

Sun, H., Zhu, Y., Yin, T., Sledge, G., and Yang, Y.-C. 1998. MRG1, the product of a melanocyte-specific gene related gene, is a cytokine-inducible transcription factor with transforming activity. Proc. Nat1. Acad. Sci. 95: 13555-13560.

Tora, L., White, J., Brou, C., Tasset, D., Webster, N., Scheer, E., and Chambon, P. 1989. The human estrogen receptor has two independent nonacidic transcriptional activation functions. Cell 59: 477-487.

White, R., Jobling, S., Hoare, S.A., Sumpter, J.P., and Parker, M.G. 1994. Environmentally persistent alkylphenolic compounds are estrogenic. Endocrinology 135: 175-182.

Yahata, T., Kurabayashi, T., Honda, A., Tojo, Y., Tanaka, K., and Abo, T. 1996. Physiological dose of estrogen regulates extrathymic T cells in female mice. Cell. Immunol. 171: 269-276.
Yahata, T., de Caestecker, M.P., Lechleider, R.J., Andriole, S. Roberts, A.B., Isselbacher, K.J., and Shioda, T. 2000. The MSG1 non-DNA-binding transactivator binds to the p300/ CBP coactivators, enhancing their functional link to the Smad transcription factors. J. Biol. Chem. 275: 8825-8834.

Yeh, S., Kang, H.Y., Miyamoto, H., Nishimura, K., Chang, H.C., Ting, H.J., Rahman, M., Lin, H.K., Fujimoto, N., Hu, Y.C., et al. 1999. Differential induction of androgen receptor transactivation by different androgen receptor coactivators in human prostate cancer DU145 cells. Endocrine 11: 195-202. 


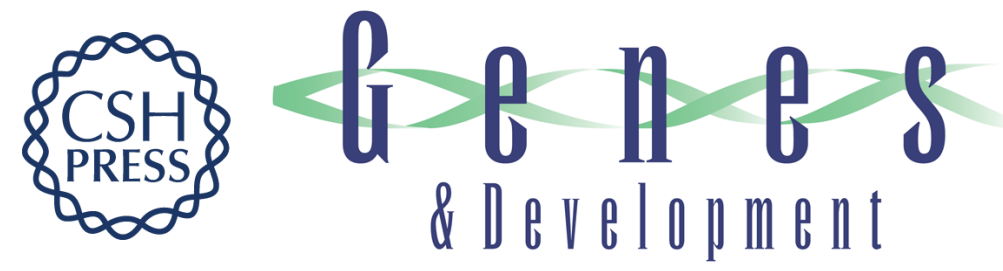

\section{Selective coactivation of estrogen-dependent transcription by CITED1 CBP/p300-binding protein}

Tetsuro Yahata, Wenlin Shao, Hideaki Endoh, et al.

Genes Dev. 2001, 15:

Access the most recent version at doi:10.1101/gad.906301

References

This article cites 41 articles, 17 of which can be accessed free at: http://genesdev.cshlp.org/content/15/19/2598.full.html\#ref-list-1

License

Email Alerting

Receive free email alerts when new articles cite this article - sign up in the box at the top Service right corner of the article or click here.

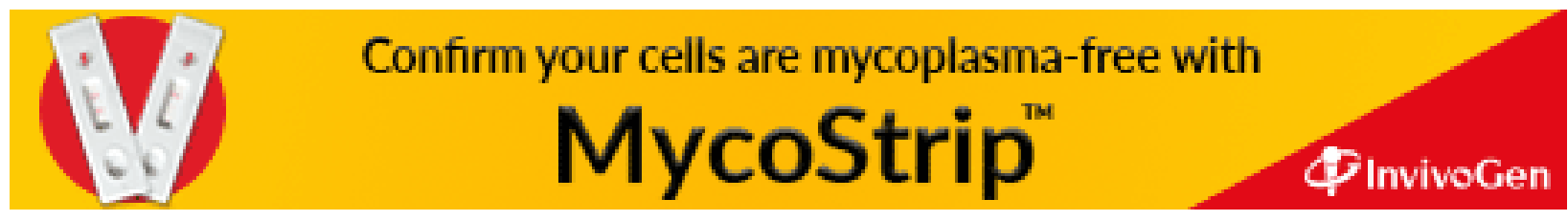

